Profit Taxation and Bank Risk Taking

Michael Kogler

December 2019 Discussion Paper no. 2019-18

School of Economics and Political Science, Department of Economics 


$\begin{array}{ll}\text { Editor: } & \text { Vanessa Pischulti } \\ & \text { University of St.Gallen } \\ & \text { School of Economics and Political Science } \\ & \text { Department of Economics } \\ & \text { Müller-Friedberg-Strasse 6/8 } \\ & \text { CH-9000 St.Gallen } \\ & \text { Phone +4171 224 23 07 } \\ & \text { Email seps@unisg.ch } \\ & \text { School of Economics and Political Science } \\ & \text { Department of Economics } \\ & \text { University of St.Gallen } \\ \text { Publisher: } & \text { Müller-Friedberg-Strasse 6/8 } \\ & \text { CH-9000 St.Gallen } \\ & \text { Phone +41 71 224 23 07 } \\ & \text { http://www.seps.unisg.ch }\end{array}$




\title{
Profit Taxation and Bank Risk Taking ${ }^{1}$
}

\author{
Michael Kogler
}

$\begin{array}{ll}\text { Author's address: } & \text { Michael Kogler, Ph.D. } \\ \text { Institute of Economics (FGN) } & \text { University of St.Gallen } \\ & \text { Varnbüelstrasse 19 } \\ & \text { CH-9000 St.Gallen } \\ & \text { Phone }+41712242753 \\ & \text { Fax } \quad+41712242887 \\ & \text { Email michael.kogler@unisg.ch } \\ & \text { Website } \underline{\text { www.fgn.unisg.ch }}\end{array}$

\footnotetext{
${ }^{1}$ I am grateful to Michael Devereux, Christian Keuschnigg, Olli Ropponen, and to participants at the ZEW Public Finance Conference in Mannheim, the Public Economic Theory Conference (APET) in Strasbourg, the congress of the IIPF in Glasgow, and the annual conference of the Verein für Socialpolitik in Leipzig and seminar participants at University of St.Gallen for helpful comments and discussions. Financial support by the Swiss National Science Foundation (projects no. P2SGP1_171927 and 100018_189118) is gratefully acknowledged.
} 


\begin{abstract}
How can tax policy improve financial stability? Recent studies point to large potential stability gains from a reform that eliminates the debt bias in corporate taxation. It is well known that such a reform reduces bank leverage. This paper analyzes a novel, complementary channel: bank risk taking. We model the portfolio choice of banks under moral hazard and thereby emphasize the "incentive function" of equity. We find that (i) an allowance for corporate equity (ACE) and a lower corporate tax rate discourage risk taking and offer stability and welfare gains, (ii) a revenue-neutral introduction of the ACE unambiguously improves financial stability, and (iii) capital regulation and deposit insurance importantly influence the tax sensitivities of bank risk taking.
\end{abstract}

\title{
Keywords
}

Corporate taxation, tax reform, banking, risk taking, financial stability

\section{JEL Classification}

G21, G28, H25 


\section{Introduction}

Taxes influence bank behavior and financial stability. In particular, corporate taxation is usually not neutral with respect to the capital structure because in most countries the interest expense on debt is tax-deductible, whereas the cost of equity is not. This wellknown debt bias creates an incentive for banks and non-financial firms to rely on debt instead of equity and may contribute to the build-up of excessive leverage. It conflicts with the primary goal of prudential regulation, namely, strengthening the capitalization and resilience of banks. According to studies in the aftermath of the financial crisis (e.g., Langedijk et al., 2015), a tax reform that eliminates the debt bias like an allowance for corporate equity (ACE) promises large potential financial stability gains.

One can think of at least two sources of such stability gains at the individual bank level: Whenever a bank increases equity after a tax reform, it can better absorb losses and becomes mechanically more stable. In addition, it may also have more 'skin in the game' leading to stronger incentives for investing a safer, better diversified portfolio. While the first channel is well understood, little is known about how the corporate income tax affects bank risk taking and portfolio quality.

The present paper studies the risk-taking channel of corporate taxation. Our analysis aims at evaluating potential financial stability and welfare gains from tax policy resulting from improved risk-taking incentives and reduced portfolio risk. Specifically, we distinguish between the effects of a tax reform, namely, an allowance for corporate equity, and of changes in tax rates. The allowance grants a partial or full deduction of the notional cost of equity from the tax base and thereby mitigates the debt bias. Furthermore, the paper examines the interaction of corporate taxation with capital regulation and deposit insurance, which are distinctive of banks and influence the tax sensitivities of risk taking. 
This paper develops a principal-agent model of bank risk taking. A bank can invest either in a prudent or in a gambling portfolio and faces a trade-off between risk and return. The gambling portfolio is riskier but offers a better chance for a high return. Moral hazard emerges because depositors only observe the realized return but not the underlying portfolio choice. Indebted banks thus have an incentive for gambling. The use of equity is solely motivated by the 'incentive function': It raises a bank's 'skin in the game', alleviates moral hazard, and avoids gambling.

With a discrete portfolio choice, we emphasize risk taking at the extensive margin and picture differences in bank profitability as a source of heterogeneity. This approach rationalizes different risk-taking strategies in equilibrium and is consistent with several interpretations (e.g., charter value, market power).

Our analysis yields three main results: First, a larger allowance for corporate equity (ACE) discourages risk taking as more banks prefer the prudent over the gambling portfolio. It thus promises financial stability and welfare gains. A lower corporate tax rate has comparable effects. Intuitively, both policies mitigate the debt bias and thereby facilitate the use of equity in setting proper risk-taking incentives.

Second, risk taking is insensitive to a neutral corporate income tax, which allows for the deduction of the entire costs of debt and equity and falls on rents. This finding echoes an earlier neutrality result in the business taxation literature (Bond and Devereux, 1995). Consequently, a revenue-neutral tax reform that (i) introduces a full ACE and (ii) raises tax rates to compensate for a potential revenue shortfall unambiguously reduces risk taking and improves financial stability.

Third, capital regulation and deposit insurance influence how banks respond to taxes, in particular, to changes in the corporate tax rate. Intuitively, satisfying capital require- 
ments is more costly for gambling banks because they must offer shareholders higher returns that are only partly tax-deductible. Since the debt bias ceteris paribus hurts them relatively more, a higher tax rate may reduce risk taking once capital requirements are tight. Deposit insurance, in turn, typically entails an implicit subsidy for banks proportional to their deposits. Since a higher tax rate permits prudent banks to reduce equity without weakening incentives, they benefit from a larger subsidy. A tax hike may therefore reduce risk taking whenever the share of guaranteed deposits is large and the subsidy strongly increases in the tax rate.

This paper connects to both the tax and the banking literature. Theoretical and empirical research in public economics suggests that the debt bias in corporate income taxation contributes to inefficiently high leverage of firms (see surveys by Auerbach, 2002; Graham, 2003, 2008). These findings have motivated several reform proposals for a more neutral tax system like the aforementioned allowance for corporate equity.

Although the capital structure of banks is constrained by regulation unlike that of nonfinancial firms, it is sensitive to corporate taxes. Keen and de Mooij (2016) examine the joint effects of regulatory constraints and the debt bias on the capital structure of banks. Their theoretical analysis highlights that capital-abundant banks with large voluntary equity buffers are more responsive to taxation than those with small buffers, the capital structure of which is often dictated by capital requirements. Using a cross-country sample of banks, they estimate tax elasticities of bank leverage between 0.14 in the short and 0.25 in the long run. These effects are driven by capital-abundant banks. Other studies that explore cross-country differences in tax rates find comparable elasticities (e.g., Hemmelgarn and Teichmann, 2014; Gu et al., 2015; Horváth, 2018). Bond et al. (2016) consider the Italian tax on productive activities, which also exhibits a debt bias, 
and estimate similar effects especially for capital-abundant banks.

These studies generally use cross-country or regional variations in corporate tax rates. An alternative approach exploits tax reforms: Schepens (2016) studies the introduction of an ACE in Belgium 2006 and finds significant increases in bank equity. Martin-Flores and Moussu (2018) find comparable effects of a tax allowance on marginal equity that existed in Italy between 1997 and 2002.

Such findings suggest that a tax reform promises large potential financial stability gains: The empirical results of De Mooij et al. (2014) imply that an ACE can significantly reduce the likelihood and the expected output losses of a financial crisis. According to Langedijk et al. (2015), such a reform may decrease the fiscal costs of financial crises (e.g., for recapitalization or bailouts) in the range of 40 to 77 percent.

A complementary source of stability gains usually not considered in these quantitative studies is lower asset risk. Empirical evidence from Belgium (Schepens, 2016; Célérier et al., 2019) and Italy (Martin-Flores and Moussu, 2018) implies that introducing an ACE improves the quality of loan portfolios reflected in a significant reduction in the share of non-performing loans and an increase in the Z-score. However, only few studies analyze the effects of the corporate tax rate on portfolio quality, and the evidence is mixed (Horváth, 2018; Gambacorta et al., 2017).

In this context, some authors also consider a related outcome, namely, the composition of portfolios between loans and securities, and point to the role of risk weights in capital regulation. A declining cost of equity relaxes binding regulatory constraints. As a result, banks allocate the additional equity to assets - typically loans - with higher risk weights. Research shows that an ACE (Célérier et al., 2019) or a levy on bank liabilities (Devereux et al., 2015) tend to increase the portfolio share of loans. ${ }^{1}$

\footnotetext{
${ }^{1}$ In a similar spirit, Horváth (2018) argues that a higher corporate tax rate tightens regulatory con-
} 
The present paper sets out one of the first theoretical models of corporate taxation and bank risk taking and sheds light on the financial stability and welfare implications of taxes. While the well-understood effects of taxation on the capital structure play an important role in our analysis, we take a entirely different route: We emphasize the 'incentive function' of equity in alleviating moral hazard as a novel channel through which taxation may enhance financial stability and abstract from the more conventional role of equity as a 'buffer'. Our main findings are consistent with the empirical evidence, and especially the extensions with bank regulation and deposit insurance can rationalize the mixed evidence on how the corporate tax rate affects risk taking.

Compared to the mean-variance model of Célérier et al. (2019), our approach differs in at least three ways: First, we consider another outcome, namely, the choice between portfolios with distinct risk and return characteristics that determine the risk of bank failure instead of portfolio allocation. Second, the main channel is fundamentally different: In line with banking theory, we model risk taking as an agency problem rather than as being driven by differences in regulatory risk weights. Third, our analysis is informative about banks that are capital-abundant banks and especially responsive to taxation (e.g., Keen and de Mooij, 2016) or constrained by the new leverage ratio in Basel III based on total rather than risk-weighted assets.

Moreover, our work builds on the theoretical banking literature, which provides a comprehensive analysis of risk taking typically modeled as the portfolio choice of banks. Risk taking is usually not contractible giving rise to moral hazard and inducing indebted banks to take excessive risks (risk shifting). Hence, a high capital ratio and large future profits of banks reflected in the charter value alleviate moral hazard and discourage risk taking (Hellmann et al., 2000). The theoretical literature has especially emphasized comstraints thereby inducing banks to shift funds from loans to securities. 
petition in deposit and loan markets (e.g., Keeley, 1990; Allen and Gale, 2000; Repullo, 2004; Boyd and De Nicolò, 2005) and capital regulation (e.g., Besanko and Kanatas, 1996; Repullo, 2004; Hakenes and Schnabel, 2011; Repullo, 2013), which both influence capital structure and charter value, as more fundamental determinants of bank risk taking.

The present paper shares several key model elements with the risk-taking literature. The disciplining role of bank equity in alleviating risk shifting is especially important for our reasoning because taxes influence the capital structure of banks and thereby risktaking incentives. Our analysis contributes to this literature as it identifies corporate taxation as a novel institutional determinant of risk taking in addition to established factors like competition, regulation, and deposit insurance.

The remainder of this paper is organized as follows: Section 2 sets out the model. Section 3 introduces the corporate income tax and derives its effects on bank risk taking, financial stability, and welfare. Section 4 adds two extensions with capital regulation and deposit insurance. Eventually, Section 5 concludes.

\section{Model}

At the core of the model is a bank's decision whether to invest in a prudent or in a gambling portfolio. The portfolios differ in their risk-return profiles, and banks face the classical trade-off between risk and return. The portfolio choice is unobservable giving rise to moral hazard. The bank's capital structure can thus importantly influence risktaking incentives. Banks raise deposits and equity, which are both elastically supplied and require the same expected return at the outset. The debt bias in corporate taxation will provide a microfoundation for a higher cost of equity. 


\subsection{Banks and Portfolios}

There is a continuum of measure one of banks. Each is operated by a license holder with no private wealth (bank owner), who is the residual claimant. A bank raises funds of size one consisting of deposits $d$ and equity $e$, which require an expected return of $1+r$. Since deposits are risky, the bank must offer a risk-adjusted interest rate $i$.

Subsequently, the bank can invest in either a prudent or a gambling portfolio. Portfolio $j=\{P, G\}$ offers (i) an intermediate payoff $1+\alpha_{m}>1+r$ with probability $\theta_{m}^{j}$, (ii) a high payoff $1+\alpha_{h}>1+\alpha_{m}$ with probability $\theta_{h}^{j}$, and (iii) zero with the complementary probability $\theta_{l}^{j}=1-\theta_{h}^{j}-\theta_{m}^{j}$. Figure 1 illustrates. In case of a zero payoff, the bank cannot repay outstanding deposits and fails. Consistent with our focus on risk taking, the possibility of failure arises from risky assets rather than from liquidity or funding risk. We define the solvency probability as $\theta^{j} \equiv \theta_{h}^{j}+\theta_{m}^{j}$ and the expected net portfolio return as $r^{j} \equiv \theta^{j}\left(1+\alpha_{m}\right)+\theta_{h}^{j}\left(\alpha_{h}-\alpha_{m}\right)-(1+r)$.

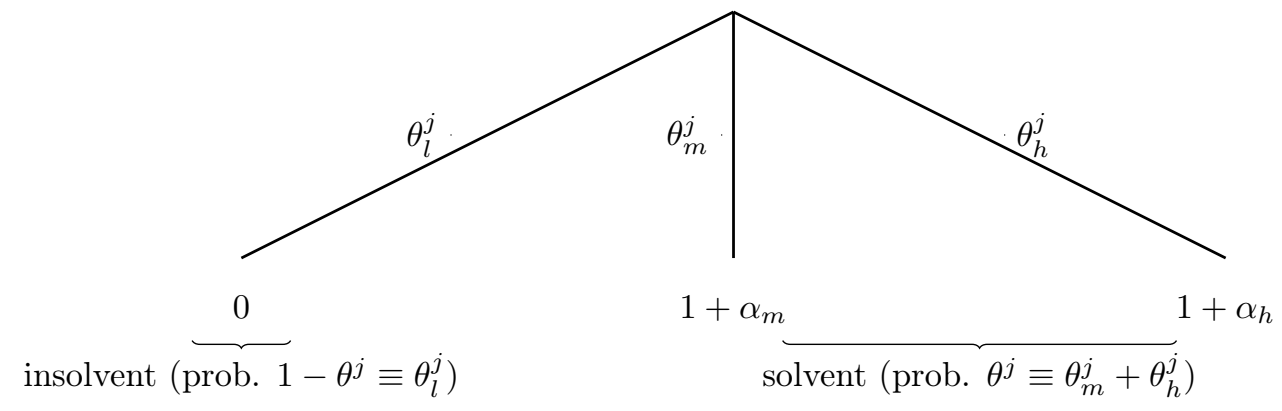

Figure 1: Portfolio Returns

Portfolio $j=\{G, P\}$ offers the high (gross) return $1+\alpha_{h}$ with probability $\theta_{h}^{j}$, the intermediate return $1+\alpha_{m}$ with probability $\theta_{m}^{j}$, and zero else.

The payoffs of the two portfolios are the same but the corresponding probabilities are drawn from two different distributions:

ASSUMPTION 1 The gambling portfolio is more likely to offer the high payoff, $\theta_{h}^{G}>$ $\theta_{h}^{P}$, but less likely to offer the intermediate payoff than the prudent portfolio, $\theta_{m}^{G}<\theta_{m}^{P}$. 
The probability of a positive payoff is higher when investing in the prudent portfolio, $\theta^{P} \equiv \theta_{h}^{P}+\theta_{m}^{P}>\theta_{h}^{G}+\theta_{m}^{G} \equiv \theta^{G}$

There is a trade-off between risk and return: Gambling banks have a better chance to earn an extra return $\Delta \alpha \equiv \alpha_{h}-\alpha_{m}$ but exhibit a higher risk of a zero return and insolvency. Intuitively, the prudent asset represents a well-diversified loan portfolio, whereas the gambling portfolio consists of more correlated loans subject to common shocks. To assure an interior solution, we assume that the expected net return on the gambling is not lower than on the prudent portfolio, $r^{G} \geq r^{P}$.

Outsiders observe the realized payoff, which is necessary for taxation, but not the portfolio. As the set of payoffs is the same for both portfolios, they cannot infer the underlying portfolio choice from the realized return. ${ }^{2}$ The latter creates a moral hazard problem that makes risk taking sensitive to the bank's capital structure. Given the same set of payoffs, modeling three instead of two outcomes ensures that the gambling is not strictly dominated by the prudent portfolio because of its lower success probability.

With a discrete portfolio choice, the model pictures the extensive margin of risk taking. This requires heterogeneous banks. We follow Repullo (2013) and introduce differences in bank profitability:

ASSUMPTION 2 Each solvent bank earns a specific return $\Omega$ in addition to the portfolio return. Types are observable and distributed on $[0, \bar{\Omega}]$ with cumulative density $F(\Omega)$.

In total, a bank of type $\Omega$ earns $1+\alpha_{m}+\Omega$ or $1+\alpha_{h}+\Omega$ if its portfolio return is intermediate or high, respectively. If the latter is zero, the bank-specific return $\Omega$ is forgone. This

\footnotetext{
${ }^{2}$ This requires that all three payoffs have a strictly positive probability and does not allow for a safe prudent portfolio with $\theta_{m}^{P}=1$ or $\theta^{P}=1$. Outsiders could otherwise infer gambling from a zero return.
} 
assumption ensures that types influence risk taking: Banks with the potential to earn high additional returns are ceteris paribus less inclined to gamble. This general approach is consistent with several interpretations:

- Costs of loan collection and ex post monitoring of borrowers: Banks incur some costs to ensure the proper repayment of loans in the spirit of Diamond (1984). ${ }^{3} \mathrm{~A}$ low specific return $\Omega$ characterizes banks with high costs of loan collection.

- Charter values: The specific return may represent the present value of future profits in reduced form. Differences in charter values may reflect different future profit opportunities or discount factors of shareholders. Appendix B explores this aspect in a dynamic model variant and provides a microfoundation for the specific return.

- Market power: Banks earn rents due to imperfect competition, for example, by charging higher loan rates that magnify the portfolio returns. They may operate in market segments that differ in the intensity of competition (e.g., number of banks, alternative sources of funding) leading to heterogeneous rents.

The timing is as follows: (i) banks attract deposits and equity and specify the deposit interest rate, (ii) banks choose the portfolio, and (iii) returns are realized.

\subsection{Risk Taking}

For any given deposit interest rate $i$ and capital ratio $e$, the expected profit of a bank of type $\Omega$ that invests in portfolio $j=\{G, P\}$ equals:

$$
\begin{aligned}
\pi^{j}(e, i ; \Omega) & =\theta^{j}\left[1+\alpha_{m}+\Omega-(1+i)(1-e)\right]+\theta_{h}^{j} \Delta \alpha-(1+r) e \\
& =r^{j}+\theta^{j} \Omega+\left[(1+r)-\theta^{j}(1+i)\right](1-e) .
\end{aligned}
$$

\footnotetext{
${ }^{3}$ Suppose the bank learns the share of performing loans (high, intermediate, zero) but observes the state of each individual loan only at a cost (auditing). No cost is incurred in the bad state where all borrowers default. Otherwise, the bank audits all borrowers to ensure repayment of the performing loans.
} 
With probability $\theta^{j}=\theta_{h}^{j}+\theta_{m}^{j}$, the bank earns at least the intermediate return $1+\alpha_{m}$ plus its specific return $\Omega$ and repays deposits $1+i$; with probability $\theta_{m}^{j}$, it receives the extra return $\Delta \alpha=\alpha_{h}-\alpha_{m}$ as well. Outside shareholders are promised an expected return on equity of $1+r{ }^{4}$ The second line rewrites profit as the total economic returns, $r^{j}+\theta^{j} \Omega$, plus a limited liability effect from a potential default on deposits.

Portfolio Choice and Capital Structure: The portfolio choice is not contractible, which causes moral hazard (risk shifting). A bank with capital ratio $e$ and deposit rate $i$ invests in the prudent portfolio if $\pi^{P}(e, i ; \Omega) \geq \pi^{G}(e, i ; \Omega)$ or, after rearranging and dividing by $\Delta \theta \equiv \theta^{P}-\theta^{G}>0$,

$$
\tilde{r}+(1+i)(1-e) \leq \Omega, \quad \tilde{r} \equiv \frac{r^{G}-r^{P}}{\Delta \theta} \geq 0
$$

This no-gambling condition ensures that the gains from risk taking on the left-hand side must be smaller than the expected loss of the bank-specific return $\Delta \theta \Omega$. Gains result from the higher expected return of the gambling portfolio if $r^{G}>r^{P}$ (i.e., $\tilde{r}>0$ ) and from the typical risk-shifting effect due to limited liability (i.e., the gambling bank defaults more often on deposits), $\Delta \theta(1+i)(1-e)$.

Equity provides discipline and alleviates risk shifting because it diminishes the gains from exploiting limited liability. Solving (2) for e defines the minimum capital ratio that ensures no gambling:

$$
e \geq e_{0}(i ; \Omega) \equiv 1+\frac{\tilde{r}-\Omega}{1+i}
$$

Only a bank with a capital ratio of at least $e_{0}$ will choose the prudent portfolio. Otherwise, gambling is privately optimal. Minimum equity decreases in the bank's type $\Omega$. Intuitively, banks with profitable (future) lending opportunities already have a strong

\footnotetext{
${ }^{4}$ This is equivalent to a more detailed formulation like in Repullo (2013), who explicitly pictures that outside equityholders are promised a share $z$ of profits $\pi$ satisfying their participation constraint $z \pi=(1+r) e$, and that bank owners maximizes their expected surplus $(1-z) \pi$.
} 
incentive to avoid failure.

Some banks with a very high specific return always prefer the prudent portfolio even with no equity. The risk of losing this return is so large that they are always better off by choosing the safer portfolio. The zero-equity cut-off

$$
\Omega^{\circ}(i)=1+i+\tilde{r}
$$

pins down the type which prefers the prudent portfolio without equity, $e_{0}\left(i ; \Omega^{\circ}\right)=0$.

In contrast, low types with $\Omega<\tilde{r}$ cannot be provided with incentives for the prudent portfolio even if they are completely financed with equity. As long as gambling is more profitable, $\tilde{r}>0$, such banks always opt for this portfolio.

Bank Value and Deposit Rate: In the beginning, the bank raises deposits $d$ and equity $e$ and needs to specify a deposit rate $i$. Depositors require a compensation for bearing the risk of bank failure to ensure an expected return of $r$ :

$$
1+r=\theta^{j}\left(1+i^{j}\right)
$$

The risk-adjusted deposit rate $i^{j}$ depends on the subsequent portfolio choice $j=\{G, P\}$. Due to $\theta^{P}>\theta^{G}$, a gambling bank pays a higher deposit rate, $i^{G}>i^{P}$. Consequently, expected bank profit in (1) coincides with the economic return, $\pi^{j}=r^{j}+\theta^{j} \Omega$.

However, risk taking is not observable and banks take capital structure and interest rate as given when deciding about the portfolio. Such a time line is typical for many principal-agent models of bank risk taking (e.g., Hakenes and Schnabel, 2011; Repullo, 2013; Martinez-Miera and Repullo, 2017). Therefore, depositors cannot condition the interest rate directly on the portfolio choice. They instead impose the minimum equity requirement (3) and charge the low interest rate $i^{P}$ only if a bank is sufficiently capitalized with $e \geq e_{0}\left(i^{P}, \Omega\right)$. Depositors anticipate that it will subsequently choose the prudent 
portfolio. Otherwise, they expect gambling and charge the high deposit rate $i^{G}$.

Each bank therefore chooses between two options: First, a bank that intends to invest in the prudent portfolio can attract deposits at the high interest rate $i^{P}$ if its capital ratio satisfies $e \geq e_{0}\left(i^{P} ; \Omega\right)$. Substituting for $i^{P}$ gives the constrained maximization problem

$$
V^{P}(\Omega)=\max _{e, \lambda} \pi^{P}\left(e, i^{P} ; \Omega\right)+\lambda^{P}\left[e-e_{0}\left(i^{P} ; \Omega\right)\right]
$$

with $\pi^{P}\left(e, i^{P} ; \Omega\right)=r^{P}+\theta^{P} \Omega$ on account of (1) and (5) and $\lambda^{P}$ denoting the multiplier. The first-order condition for equity implies $\lambda^{P}=0$, and any capital ratio $e \geq e_{0}\left(i^{P} ; \Omega\right)$ is optimal. Banks may raise equity in excess of $e_{0}$ as it is no more expensive than debt. The ex ante value equals the economic return, $V^{P}(\Omega)=r^{P}+\theta^{P} \Omega$.

Second, consider a bank that plans to invest in the gambling portfolio. It needs to offer depositors the high interest rate $i^{G}$ and its capital ratio satisfies $e<e_{0}\left(i^{G} ; \Omega\right)$. The constrained maximization problem is

$$
V^{G}(\Omega)=\max _{e, \lambda} \pi^{G}\left(e, i^{G} ; \Omega\right)+\lambda^{G}\left[e_{0}\left(i^{G} ; \Omega\right)-e\right]
$$

with $\pi^{G}\left(e, i^{G} ; \Omega\right)=r^{G}+\theta^{G} \Omega$. Again, one obtains $\lambda^{G}=0$ such that any capital ratio $e<e_{0}\left(i^{G} ; \Omega\right)$ is optimal. The corresponding bank value is $V^{G}(\Omega)=r^{G}+\theta^{G} \Omega$.

Equations (6) and (7) characterize two options - combinations of capital structure, deposit rate, and portfolio choice - that are incentive-compatible and profit-maximizing. Each bank initially compares them and decides whether it (i) raises equity $e \geq e_{0}$, offers the low deposit rate $i^{P}$, and invests in the prudent portfolio or (ii) raises little or no equity, offers the high deposit rate $i^{G}$, and gambles.

\subsection{Equilibrium}

A bank's type $\Omega$ influences the ex ante bank value. Raising equity and investing in the prudent portfolio yields a higher value for some types, while gambling is more attractive 
for others. The pivotal type $\Omega^{*}$ is indifferent between the two portfolios, $V^{P}\left(\Omega^{*}\right)=$ $V^{G}\left(\Omega^{*}\right)$. Substituting for the ex ante values yields the risk-taking cut-off:

$$
\Omega^{*}=\tilde{r}
$$

The expected gains from gambling, $r^{G}-r^{P}$, exactly offset the loss of the specific return, $\Delta \theta \Omega$. High types, $\Omega \geq \Omega^{*}$, choose the prudent option, whereas low types, $\Omega<\Omega^{*}$, gamble provided that gambling is more profitable (i.e., $\tilde{r}>0$ ). At least some prudent banks need to raise positive equity to have proper incentives because the risk-taking is smaller than the zero-equity cut-off, $\Omega^{*}<\Omega^{\circ}\left(i^{P}\right)=(1+r) / \theta^{P}+\Omega^{*}$. Substituting (8) into minimum equity (3) reveals that the pivotal bank is all-equity financed, $e\left(\Omega^{*}\right)=1$. Consequently, three groups of banks emerge in equilibrium:

- $\Omega \geq \Omega^{\circ}\left(i^{P}\right)$ : Highly profitable banks invest in the prudent portfolio even without attracting any equity.

- $\Omega^{\circ}\left(i^{P}\right)>\Omega \geq \Omega^{*}$ : The bank-specific return alone is not large enough to provide discipline. Such banks have a strictly positive capital ratio, $e \geq e_{0}>0$, and choose the prudent portfolio.

- $\Omega<\Omega^{*}$ : Rather unprofitable banks gamble and have a capital ratio below $e_{0}$.

\section{Corporate Income Tax}

This section introduces the corporate income tax, which potentially discriminates between debt and equity ('debt bias'). The tax rate equals $\tau$, and the tax base is profit equal to realized payoff, which is either $\alpha_{m}+\Omega$ or $\alpha_{h}+\Omega$, net of the interest expense on deposits, $i(1-e)$. In addition, a fraction $s \in[0,1]$ of the notional cost of equity is tax-deductible. The latter is equal to the risk-adjusted return on equity and coincides with the deposit 
interest rate $i$. After all, both types of funds require the same expected return at the outset. Banks can thus deduct a total cost of equity sie from the tax base. The parameter $s$ characterizes the tax allowance $(\mathrm{ACE}): s<1$ corresponds to a distortionary tax that exhibits a debt bias, whereas $s=1$ describes a neutral tax that allows for the deduction of the entire cost of capital and exclusively falls on economic rents.

We consider a tax only levied on profits but not on losses. Although firms that incur losses might use them to offset future profits for tax purposes (loss carry forward) or receive a tax rebate in reality, this approach is consistent with the static model. Furthermore, we highlight insolvency rather than 'regular losses', and any tax rebate would be paid out to the creditors of a failed bank and affect the pricing of deposits. The asymmetric tax treatment of profits and losses, however, requires that banks can deduct the risk-adjusted interest rate $i$ instead of the risk-free rate $r$. This property differs from the neutral business tax suggested by Bond and Devereux (1995) that grants a rebate on losses and allows only for the deduction of the risk-free rate of return. Appendix B demonstrates that both systems are equivalent and lead to the very same risk-taking decisions once there is a full allowance for equity, $s=1$.

Given these assumptions, the tax liability depending on the realized return is:

$$
T_{m}=\tau\left[\alpha_{m}+\Omega-i(1-e)-s i e\right], \quad T_{h}=\tau\left[\alpha_{h}+\Omega-i(1-e)-s i e\right], \quad T_{l}=0 .
$$

A bank's expected tax burden when investing in portfolio $j=\{G, P\}$ is $T^{j}=\theta_{m}^{j} T_{m}+$ $\theta_{h}^{j} T_{h}=\theta^{j} T_{m}+\theta_{h}^{j} \tau \Delta \alpha$. After substituting and collecting terms, one obtains:

$$
T^{j}=\tau\left[r^{j}+\theta^{j} \Omega+(1+r)-\theta^{j}(1+i)+(1-s) \theta^{j} i e\right]
$$

As long as the tax is distortionary with $s<1$, equity increases the expected tax burden. Otherwise, the tax base is independent of the capital structure. 


\subsection{Risk Taking}

Noting (1), the after-tax profit from investing in portfolio $j$ equals

$$
\begin{aligned}
\pi^{j}(e, i ; \Omega) & =r^{j}+\theta^{j} \Omega+\left[(1+r)-\theta^{j}(1+i)\right](1-e)-T^{j} \\
& =(1-\tau)\left(r^{j}+\theta^{j} \Omega\right)+\left[(1+r)-\theta^{j}(1+i)\right](1-\tau-e)-\tau(1-s) \theta^{j} i e .
\end{aligned}
$$

Portfolio Choice and Capital Structure: For a given deposit rate and capital ratio, the bank of type $\Omega$ chooses the prudent portfolio as long as $\pi^{P}(e, i ; \Omega)-\pi^{G}(e, i ; \Omega) \geq 0$. Substituting (10) and (11) and dividing by $\Delta \theta$ yields the no-gambling condition:

$$
(1-\tau) \tilde{r}+(1+i)(1-e)-\tau[1+i-(1-s) i e] \leq(1-\tau) \Omega
$$

The gains from gambling on the left-hand side reflect a higher expected return on the gambling portfolio, $\tilde{r} \geq 0$, and more opportunities to default and not repay deposits, $(1+i)(1-e)$. Taxes diminish these gains but they also hurt prudent banks via the specific return $(1-\tau) \Omega$. Intuitively, taxes diminish rents due to market power or future profits, which disproportionately reduces expected profits of prudent banks.

Solving (12) yields the minimum capital ratio which prevents gambling

$$
e \geq e_{0}(i ; \Omega) \equiv \frac{(1-\tau)(1+i+\tilde{r}-\Omega)}{1+i^{\prime}}, \quad i^{\prime} \equiv i[1-\tau(1-s)]
$$

Minimum equity is zero, $e_{0}\left(i ; \Omega^{\circ}\right)=0$, whenever the bank-specific return is large enough, $\Omega>\Omega^{\circ}=1+i+\tilde{r}$.

Bank Value and Deposit Rate: Each bank chooses between two incentive-compatible and profit-maximizing options. First, a bank which invests in the prudent portfolio offers the deposit rate $1+i^{P}=(1+r) / \theta^{P}$ and must have a minimum capital ratio $e \geq e_{0}\left(i^{P} ; \Omega\right)$,

$$
V^{P}(\Omega)=\max _{e, \lambda} \pi^{P}\left(e, i^{P}, \Omega\right)+\lambda^{P}\left[e-e_{0}\left(i^{P} ; \Omega\right)\right]
$$

with $\pi^{P}\left(e, i^{P} ; \Omega\right)=(1-\tau)\left(r^{P}+\theta^{P} \Omega\right)-\tau(1-s) \theta^{P} i^{P} e$ by $(11)$. The first-order condition implies a binding constraint, $\lambda^{P}=\tau(1-s) \theta^{P} i^{P}>0$. Since equity is more expensive than 
deposits due to the debt bias, the bank raises no more than minimum equity, $e=e_{0}$. The prudent strategy yields an ex ante value $V^{P}(\Omega)=(1-\tau)\left(r^{P}+\theta^{P} \Omega\right)-\tau(1-s)\left(1+r-\theta^{P}\right) e_{0}$. It consists of the after-tax economic return minus a term that represents the extra tax cost of equity due to the debt bias. Highly profitable banks, $\Omega \geq \Omega^{\circ}$, need no equity and accordingly incur no such cost.

The value of a prudent bank rises with the type $\Omega$ but falls with the minimum capital ratio $e_{0}$ because of the debt bias:

$$
\begin{aligned}
d V^{P}= & (1-\tau) \theta^{P} \cdot d \Omega-\tau(1-s)\left(1+r-\theta^{P}\right) \cdot d e_{0}+\tau\left(1+r-\theta^{P}\right) e_{0} \cdot d s \\
& -\left[r^{P}+\theta^{P} \Omega+(1-s)\left(1+r-\theta^{P}\right) e_{0}\right] \cdot d \tau .
\end{aligned}
$$

A larger allowance for equity $s$ directly boosts bank value by reducing the extra costs of equity, while higher tax rate $\tau$ lowers the after-tax returns and magnifies the debt bias. Once a zero capital ratio is sufficient, $\Omega>\Omega^{\circ}$, the ex ante value is insensitive to the tax allowance and responds less strongly to tax rate changes.

Second, a bank that subsequently gambles offers the high deposit rate $1+i^{G}=$ $(1+r) / \theta^{G}$ and its capital ratio satisfies $e<e_{0}\left(i^{G} ; \Omega\right)$. It maximizes

$$
V^{G}(\Omega)=\max _{e, \lambda} \pi^{G}\left(e, i^{G} ; \Omega\right)+\lambda^{G}\left[e_{0}\left(i^{G} ; \Omega\right)-e\right]
$$

with $\pi^{G}\left(e, i^{G} ; \Omega\right)=(1-\tau)\left(r^{G}+\theta^{G} \Omega\right)-\tau(1-s) \theta^{G} i^{G} e$. The first-order condition for equity implies $\lambda^{G}=-\tau(1-s) \theta^{G} i^{G}<0$. As equity is expensive, the constraint is fulfilled with zero equity giving an ex ante value equal to the economic return after taxes, $V^{G}(\Omega)=$ $(1-\tau)\left(r^{G}+\theta^{G} \Omega\right)$. The latter increases in the type and decreases in the tax rate but is insensitive to the allowance because such banks raise no equity:

$$
d V^{G}=(1-\tau) \theta^{G} \cdot d \Omega-\left(r^{G}+\Omega^{G}\right) \cdot d \tau
$$




\subsection{Equilibrium}

The pivotal type $\Omega^{*}$ is indifferent between the two options set out above, $V^{P}\left(\Omega^{*}\right)=$ $V^{G}\left(\Omega^{*}\right)$. Substituting (14) and (16) yields:

$$
\Omega^{*}=\tilde{r}+\frac{\tau(1-s)\left(1+r-\theta^{P}\right) e_{0}\left(i^{P} ; \Omega^{*}\right)}{\Delta \theta(1-\tau)} .
$$

Minimum equity $e_{0}\left(i^{P} ; \Omega^{*}\right)$ itself depends on the cut-off according to (13). The closedform solution of the risk-taking cut-off is:

$$
\Omega^{*}=\tilde{r}+\chi\left(1+i^{P}\right)
$$

$\chi \in[0,1)$ is a measure of the tax distortion reflecting the extra tax cost of equity:

$$
\chi=\frac{\tau(1-s)\left(1+r-\theta^{P}\right)}{\Delta \theta\left(1+i^{\prime}\right)+\tau(1-s)\left(1+r-\theta^{P}\right)} .
$$

Recall $i^{\prime}=i^{P}[1-\tau(1-s)]$. Only if the bank can deduct the entire cost of equity from the tax base, $s=1$, the distortion disappears, $\chi=0$, giving $\Omega^{*}=\tilde{r}$ like in the no-tax equilibrium. Therefore, a neutral tax does influence risk taking of banks.

In equilibrium, the risk-taking cut-off is always smaller than the zero-equity cut-off, $\Omega^{*}=\tilde{r}+\chi\left(1+i^{P}\right) \leq 1+i^{P}+\tilde{r} \equiv \Omega^{\circ}\left(i^{P}\right)$, due to $\chi<1$. Some banks with $\Omega \in\left(\Omega^{*}, \Omega^{\circ}\right)$ must attract some equity to set proper risk-taking incentives. Three different groups emerge in equilibrium as illustrated in Figure 2:

- $\Omega \geq \Omega^{\circ}\left(i^{P}\right)$ : Highly profitable banks do not need any equity because the risk of losing the return $\Omega$ outweighs any benefits from gambling. Accordingly, they raise no equity, opt for the prudent portfolio, and succeed with probability $\theta^{P}$.

- $\Omega^{\circ}\left(i^{P}\right)>\Omega \geq \Omega^{*}$ : The bank-specific return is not large enough to provide discipline alone. Such banks choose the prudent portfolio only with some positive equity, $e_{0}>0$. Despite an additional cost, this option is preferred to gambling. Those banks raise equity, invest in the prudent portfolio, and succeed with probability $\theta^{P}$. 
- $\Omega<\Omega^{*}$ : The bank-specific return is so small that gambling is more attractive in part because such banks would need to raise a lot of costly equity to fulfill the nogambling condition. Accordingly, these banks have no equity, gamble, and succeed with probability $\theta^{G}$.

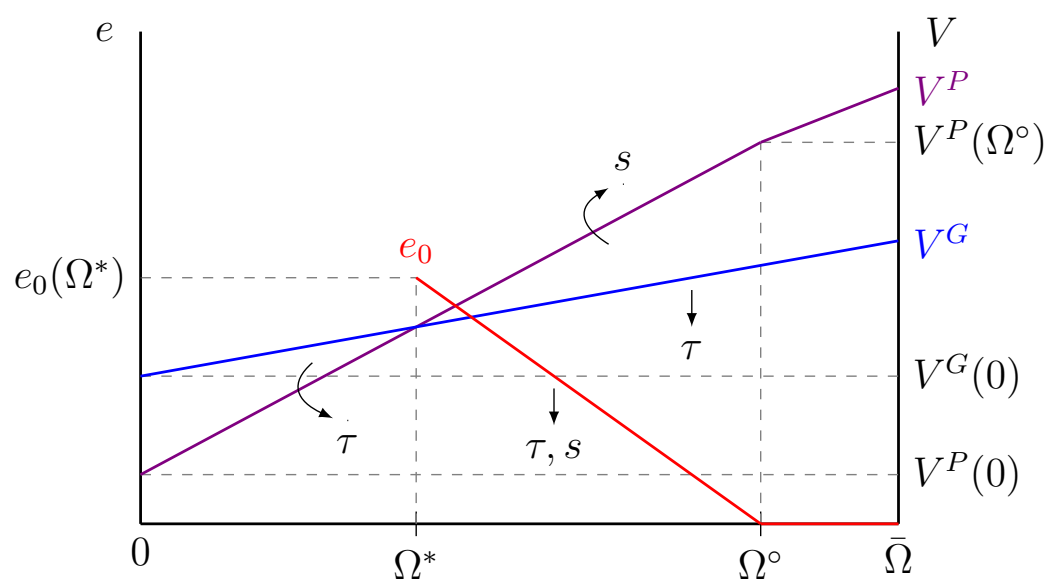

Figure 2: Equilibrium

This figure depicts minimum equity $e_{0}$ (in red, left axis) and bank values from prudent and gambling portfolio $V^{P}$ and $V^{G}$ (in blue and violet, right axis) and the risk-taking and zero-equity cut-offs $\Omega^{*}$ and $\Omega^{\circ}$ in the presence of a distorting corporate income tax with $\tau>0$ and $s<1$. The arrows indicate that a higher tax rate $\tau$ reduces both $V^{P}$ and $V^{G}$ as well as $e_{0}$ and that a larger tax allowance $s$ raises $V^{P}$ and reduces $e_{0}$.

\subsection{Results}

\subsubsection{Capital Structure and Risk Taking}

Equity helps some banks set incentives to avoid gambling. Differentiating the individual minimum equity requirement in (13) gives:

$$
d e_{0}=-\frac{1-\tau}{1+i^{\prime}} \cdot d \Omega-\frac{\tau i e_{0}}{1+i^{\prime}} \cdot d s-\frac{(1+s i) e_{0}}{(1-\tau)\left(1+i^{\prime}\right)} \cdot d \tau .
$$

It decreases in the type because a higher specific return strengthens the incentive for investing in the prudent portfolio. Taxes affects the capital ratio as follows:

LEMMA 1 The minimum capital ratio $e_{0}$ of an individual bank decreases in the corporate tax rate $\tau$ and in the allowance for equity $s$. 
Proof: Follows from Equation (21).

These sensitivities mirror how the tax affects incentives: A more generous allowance diminishes the gains from gambling because only solvent banks can make use of a larger deduction, see (12). On net, a rising tax rate also renders gambling relatively less attractive. This portfolio ceteris paribus promises higher expected returns that are disproportionately reduced by the higher tax rate. A lower capital ratio thus suffices to preserve risk-taking incentives.

To evaluate how taxes influence the portfolio choice of banks, we derive the sensitivities of the cut-off $\Omega^{*}$. If the latter increases, more banks will gamble and take risks. Starting from $d V^{P}\left(\Omega^{*}\right)=d V^{G}\left(\Omega^{*}\right)$, we substitute (15) and (17), collect terms and divide by $\Delta \theta$ :

$$
\begin{aligned}
{\left[1-\tau-\tau(1-s) \zeta \frac{d e_{0}}{d \Omega}\right] \cdot d \Omega^{*}=} & -\tau \zeta\left[e_{0}-(1-s) \frac{d e_{0}}{d s}\right] \cdot d s \\
& -\left[\tilde{r}-\Omega^{*}-(1-s) \zeta\left(e_{0}+\tau \frac{d e_{0}}{d \tau}\right)\right] \cdot d \tau .
\end{aligned}
$$

This formulation uses $\zeta \equiv\left(1+r-\theta^{P}\right) / \Delta \theta>0$. The coefficients of $s$ and $\tau$ mirror that taxes influences the relative bank values directly and via minimum equity, which is relatively expensive because of the debt bias. A larger tax allowance boosts the value of prudent banks because only such banks have equity and benefit from the smaller tax cost. Declining minimum equity $e_{0}$ reinforces this effect. A rising corporate tax rate, in turn, diminishes the expected after-tax return $(1-\tau)\left(r^{j}+\theta^{j} \Omega\right)$. For the pivotal bank, this decrease is stronger if it invests in the prudent portfolio because of a higher pre-tax return $r^{P}+\theta^{P} \Omega^{*} \geq r^{G}+\theta^{G} \Omega^{*}$ or, equivalently, $\tilde{r}-\Omega^{*}=-\chi\left(1+i^{P}\right)<0$. However, a tax hike also affects the extra costs of equity only incurred by prudent banks only, $\tau(1-s)\left(1+r-\theta^{P}\right) e_{0}$ : The higher tax rate magnifies this cost per unit of equity but lowers minimum equity $e_{0}$, which tends to offset this effect, see (21).

We summarize the net effects of taxes on risk taking in the following proposition: 
PROPOSITION 1 The risk-taking cut-off $\Omega^{*}$ responds to the tax according to

$$
d \Omega^{*}=-\sigma_{s} \cdot d s+\sigma_{\tau} \cdot d \tau
$$

with coefficients

$$
\sigma_{s}=\frac{\chi(1-\chi)\left(1+i^{P}\right)^{2}}{(1-s)\left(1+i^{\prime}\right)}>0, \quad \sigma_{\tau}=\frac{\chi(1-\chi)\left(1+i^{P}\right)^{2}}{\tau\left(1+i^{\prime}\right)}>0 .
$$

A larger allowance for equity s and a lower corporate tax rate $\tau$ unambiguously discourage risk taking. The cut-off falls, and more banks invest in the prudent portfolio.

Proof: Equation (23) and the coefficients follow from substituting the sensitivities of $e_{0}$ in $(21)$ into $(22)$. We evaluate the sensitivities at the cut-off $\Omega^{*}$ with $e_{0}\left(\Omega^{*}\right)=(1-$ $\tau)(1-\chi)\left(1+i^{P}\right) /\left(1+i^{\prime}\right)$ and use $\tilde{r}-\Omega^{*}=-\chi\left(1+i^{P}\right)$ from $(19)$

First, a more generous tax allowance mitigates the debt bias and allows for a lower capital ratio without undermining risk-taking incentives. It boosts the ex ante value from investing in the prudent portfolio but leaves the value from gambling unchanged. Raising equity and investing in the prudent portfolio becomes attractive for a larger share of banks. This finding is consistent with the empirical evidence, which suggests that introducing an ACE improves portfolio quality in terms of a declining share of nonperforming loans (e.g., Schepens, 2016; Martin-Flores and Moussu, 2018).

Second, a higher tax rate leads to more risk taking because it impairs the value of prudent relative to gambling banks. A tax hike magnifies the debt bias, and it diminishes the expected total return of prudent relative to gambling banks around the cut-off. Compared to the empirical evidence, this prediction is in line with Gambacorta et al. (2017) but conflicts with Horváth (2018). ${ }^{5}$ We further explore this aspect in two extensions (see

\footnotetext{
${ }^{5}$ Gambacorta et al. (2017) study the Italian tax on productive activities, which is quite similar to the corporate income tax, and estimate that higher tax rates impair portfolio quality reflected in a higher ratio of bad loans to total assets. Horváth (2018) provides cross-country evidence and finds a negative effect of tax rates on the share of non-performing loans.
} 
Section 4). We demonstrate, for example, that the model can rationalize a negative effect of the tax rate on risk taking once we take into account capital requirements and if the latter are sufficiently tight. After all, Gambacorta et al. (2017) observe an increase in risk taking due to higher taxes only in a subsample of weakly capitalized banks.

An important case is a neutral corporate income tax, which treats debt and equity symmetrically and allows for the deduction of the entire cost of capital:

PROPOSITION 2 If the tax system is neutral, $s=1$, bank risk taking is insensitive to the corporate tax rate.

Proof: A full ACE eliminates the tax distortion, $\chi=1$, on account of (20). Evaluating the corresponding coefficient in (23) suggests $\sigma_{\tau}=0$.

Such a neutral tax exclusively falls on economic rents, $r^{j}+\theta^{j} \Omega$. Issuing equity does not entail any extra costs that could impair the value of prudent banks. The tax proportionately scales down the ex ante values $V^{P}$ and $V^{G}$ and thereby preserves their ranking. This property echoes the central result of Bond and Devereux (1995) that a tax on economic rents does not affect risky investment decisions of firms.

The key policy implication of this finding is a revenue-neutral tax reform:

COROLLARY 1 Introducing a full allowance for corporate equity in a revenue-neutral fashion unambiguously discourages bank risk taking.

Proof: Increasing the tax allowance from $s=0$ to $s=1$ unambiguously lowers the risktaking cut-off $\Omega^{*}$, see Proposition 1. Appendix A shows that tax revenue likely shrinks, $T_{\mid s=0}-T_{\mid s=1}>0$. Once $s=1$, a tax hike has no effect on risk taking, $d \Omega^{*} / d \tau_{\mid s=1}=0$, and increases revenue, $d T / d \tau_{\mid s=1}>0$. 
How the introduction of a full allowance for corporate equity affects tax revenue is a priori unclear due to counteracting mechanical (smaller tax base) and behavioral (banks switching to the prudent portfolio with higher expected pre-tax return) effects. Nevertheless, a decline in revenue is likely unless the corporate tax rate is very high. ${ }^{6}$ To avoid a revenue shortfall, the government can increase the tax rate, which has no effect on risk taking once the tax system is neutral. The tax hike does not offset the reduction in risk taking induced by the $\mathrm{ACE}$, and it mechanically increases revenue.

\subsubsection{Financial Stability}

Reduced risk taking is a key source of stability gains from tax reform. We consider two common measures of financial stability: average failure risk and aggregate bank equity.

The average probability of bank failure $\pi$ reflects that a fraction $F\left(\Omega^{*}\right)$ of banks gambles and fails with higher probability $1-\theta^{G}$ :

$$
\pi=\left(1-\theta^{G}\right) \theta F\left(\Omega^{*}\right)+\left(1-\theta^{P}\right)\left[1-\theta F\left(\Omega^{*}\right)\right]
$$

Noting the changes in the share of gambling banks $F\left(\Omega^{*}\right)$ implied by Propositions 1 and 2 , average failure risk in the banking sector falls if the debt bias is reduced with a larger allowance for equity. A higher corporate tax rate, in contrast, has a destabilizing effect provided that the tax is distortionary.

We define aggregate equity of the banking sector as follows:

$$
\bar{e}=\int_{\Omega^{*}}^{\Omega^{\circ}} e_{0}(\Omega) d F(\Omega) .
$$

In equilibrium, only intermediate types, $\Omega \in\left(\Omega^{*}, \Omega^{\circ}\right)$, have a positive capital ratio that ranges between $e_{0}\left(i^{P} ; \Omega^{\circ}\right)=0$ and $e_{0}\left(i^{P} ; \Omega^{*}\right)=(1-\tau)(1-\chi)\left(1+i^{P}\right) /\left(1+i^{\prime}\right)<1$.

\footnotetext{
${ }^{6}$ With rather low tax rates, banks are well capitalized (see Lemma 1), and deducting the cost of equity significantly shrinks the tax base.
} 
Taxes affect the aggregate equity both at the extensive and intensive margin:

$$
d \bar{e}=\sum_{h \in\{s, \tau\}}\left[\int_{\Omega^{*}}^{\Omega^{\circ}} \frac{d e_{0}(\Omega)}{d h} d F(\Omega)-e_{0}^{*} f\left(\Omega^{*}\right) \frac{d \Omega^{*}}{d h}\right] \cdot d h
$$

The net effect is clearly negative for a higher tax rate, which reduces the share of prudent banks with positive equity as well as their capital ratio, but more ambiguous for a larger allowance because the two effects tend to offset each other.

The following corollary summarizes the financial stability effects of taxes:

COROLLARY 2 A larger allowance for corporate equity reduces the average probability of bank failure and raises the aggregate capital ratio of the banking sector. A higher tax rate increases the average probability of failure and reduces the aggregate capital ratio.

Proof: The effects on $\pi$ follow from differentiating (24) and substituting (23), which yields $d \pi=\Delta \theta f\left(\Omega^{*}\right)\left[-\sigma_{s} \cdot d s+\sigma_{\tau} \cdot d \tau\right]$. The aggregate capital ratio $\bar{e}$ falls with the tax rate on account of the lower individual capital ratio $d e_{0} / d \tau<0$ and the rising cut-off $d \Omega^{*} / d \tau>0$, see (21) and (23). Appendix A derives the effect of the allowance on the aggregate capital ratio assuming uniformly distributed types $\Omega \sim U[0, \bar{\Omega}]$.

The finding that a larger ACE reduces bank failure risk is consistent with De Mooij et al. (2014) who estimate that such reforms lower the probability of a financial crisis. The predictions about aggregate bank equity are in line with the empirical evidence, namely, positive effects of introducing an ACE (e.g., Schepens, 2016) and negative effects of a higher tax rate (e.g., Hemmelgarn and Teichmann, 2014; Keen and de Mooij, 2016; Horváth, 2018).

\subsubsection{Welfare}

Tax policy has welfare effects. Welfare equals the aggregate surplus of the banking sector plus tax revenue, $W=V+T$. Depositors and outside shareholders are adequately 
compensated and earn a zero surplus. Using the definitions

$$
V \equiv \int_{0}^{\Omega^{*}} V^{G}(\Omega) d F(\Omega)+\int_{\Omega^{*}}^{\bar{\Omega}} V^{P}(\Omega) d F(\Omega), \quad T \equiv \int_{0}^{\Omega^{*}} T^{G} d F(\Omega)+\int_{\Omega^{*}}^{\bar{\Omega}} T^{P}(\Omega) d F(\Omega),
$$

and substituting (10), (14), and (15) gives:

$$
W=\int_{0}^{\Omega^{*}} r^{G}+\theta^{G} \Omega d F(\Omega)+\int_{\Omega^{*}}^{\bar{\Omega}} r^{P}+\theta^{P} \Omega d F(\Omega) .
$$

The welfare contribution of each bank is equal to its economic return or rent. Risk taking represented by the cut-off $\Omega^{*}$ influences welfare as follows:

$$
d W=-\left(\Omega^{*}-\tilde{r}\right) \Delta \theta f\left(\Omega^{*}\right) \cdot d \Omega^{*}=-\chi\left(1+i^{P}\right) \Delta \theta f\left(\Omega^{*}\right) \cdot d \Omega^{*}<0 .
$$

The second equality substitutes (19) for $\Omega^{*}$ to get the welfare effects of risk taking in market equilibrium with taxes. Noting Proposition 1, one obtains:

COROLLARY 3 If the corporate income tax is distortionary, too many banks gamble. Increasing the allowance for equity and decreasing the tax rate reduces excessive risk taking and raises welfare.

Proof: According to Equation (28), the risk-taking cut-off is too high whenever the corporate income tax is distortionary with $s<1$ such that $\chi>0$. A larger tax allowance and a lower tax rate improve welfare because they lower $\Omega^{*}$ (see Proposition 1 ).

The debt bias is the source of excessive risk taking because it hampers the use of equity to set correct incentives and induces some banks with $\Omega \in\left[\tilde{r}, \tilde{r}+\chi\left(1+i^{P}\right)\right]$ to gamble. Without such distortions, these banks would choose the prudent portfolio.

Alleviating the debt bias thus promises welfare gains: A larger tax allowance and a lower tax rate mitigate distortions of the capital structure and discourage risk taking. With a full ACE (i.e., $s=1$ such that $\chi=0$ ), bank risk taking is efficient, $\Omega^{*}=\tilde{r}$ and $d W / d \Omega^{*}=0$. Any changes in the tax rate have no welfare implications. Therefore, a tax hike as a part of the revenue-neutral introduction of the ACE does not diminish the 
welfare gains of such a reform.

Corporate tax reform can only reduce distortions of risk taking caused by the tax system itself, namely, by the debt bias. It cannot limit the degree of bank risk taking below $\Omega^{*}=\tilde{r}$. If the latter is considered inefficiently high for reasons outside the model (e.g., social costs of bank failure), corporate tax reform alone can typically not solve this problem. Regulation or Pigovian taxes appear more suitable to address such distortions.

\section{Extensions}

This section introduces two institutional features, which are specific to banks and importantly influence capital structure and risk taking: capital requirements and deposit insurance. The extensions serve as robustness checks and aim at reconciling the model's predictions about how the corporate tax rate affects risk taking with the rather ambiguous findings in the empirical literature.

\subsection{Minimum Capital Requirements}

Suppose each bank has to maintain a capital ratio of at least $k$. Such capital requirements are similar to the leverage ratio in Basel III, which defines minimum equity relative to total (unweighted) bank assets. ${ }^{7}$ As long as capital requirements are rather low, they do not bind for all banks. Some may still need to raise voluntary equity $\varepsilon$ in excess of the regulatory minimum to set proper incentives giving a total capital ratio of $e=k+\varepsilon$.

\footnotetext{
${ }^{7}$ It would be difficult to add risk-weighted capital requirements like in Célérier et al. (2019) in this framework, in which the portfolio choice of the bank is unobservable.
} 


\subsubsection{Risk Taking}

Portfolio Choice and Capital Structure: Expected profit (11) and the no-gambling condition (12) are unchanged as they depend on the total capital ratio $e$ only. Minimum voluntary equity that ensures no gambling equals:

$$
\varepsilon \geq \varepsilon_{0}(i ; \Omega) \equiv \frac{(1-\tau)(1+i+\tilde{r}-\Omega)}{1+i^{\prime}}-k .
$$

A bank will invest in the prudent portfolio only if voluntary equity is at least $\varepsilon_{0}(i ; \Omega)$. The total capital ratio, $e_{0}=k+\varepsilon_{0}$, is independent of regulatory requirements and is solely determined by the no-gambling condition.

Capital requirements alone provide sufficient discipline for profitable banks that choose the prudent portfolio even without any voluntary equity, $\Omega \geq \Omega^{\circ}(i)=1+i+\tilde{r}-(1+$ $\left.i^{\prime}\right) k /(1-\tau)$. The respective cut-off follows from $\varepsilon_{0}\left(i ; \Omega^{\circ}\right)=0$. Obviously, the tighter capital standards are, the larger the share of such banks.

Bank Value and Deposit Rate: A prudent bank attracts deposits at the interest rate $1+i^{P}=(1+r) / \theta^{P}$ and must satisfy $\varepsilon \geq \varepsilon_{0}$. It maximizes expected bank value

$$
V^{P}(\Omega)=\max _{\varepsilon, \lambda} \pi^{P}\left(k+\varepsilon, i^{P} ; \Omega\right)+\lambda^{P}\left[\varepsilon-\varepsilon_{0}\left(i^{P} ; \Omega\right)\right]
$$

with $\pi^{P}\left(k+\varepsilon, i^{P} ; \Omega\right)=(1-\tau)\left(r^{P}+\theta^{P} \Omega\right)-\tau(1-s) \theta^{P} i^{P}(k+\varepsilon)$. The constraint binds, $\varepsilon=\varepsilon_{0}$, and investing in the prudent portfolio promises an ex ante value $V^{P}(\Omega)=$ $(1-\tau)\left(r^{P}+\theta^{P}\right) \Omega-\tau(1-s)\left(1+r-\theta^{P}\right)\left(k+\varepsilon_{0}\right)$.

A gambling bank must offer the high interest rate $1+i^{G}=(1+r) / \theta^{G}$ and solves

$$
V^{G}(\Omega)=\max _{\varepsilon, \lambda} \pi^{G}\left(k+\varepsilon, i^{G} ; \Omega\right)+\lambda\left[\varepsilon_{0}\left(i^{G} ; \Omega\right)-\varepsilon\right]
$$

with $\pi^{G}\left(k+\varepsilon, i^{G} ; \Omega\right)=(1-\tau)\left(r^{G}+\theta^{G} \Omega\right)-\tau(1-s) \theta^{G} i^{G}(k+\varepsilon)$ by (11). Capital requirements bind, $\varepsilon=0$, giving $V^{G}(\Omega)=(1-\tau)\left(r^{G}+\theta^{G} \Omega\right)-\tau(1-s)\left(1+r-\theta^{G}\right) k$.

Gambling banks exhibit a higher insolvency risk and need to compensate shareholders 
with a higher risk premium. Their risk-adjusted cost of equity, which coincides with the deposit rate, is thus higher, $i^{G}>i^{P}$. The fact that only part of this cost is tax-deductible therefore hurts gambling banks more than prudent banks:

$$
\tau(1-s) \theta^{G} i^{G}=\tau(1-s)\left(1+r-\theta^{G}\right)>\tau(1-s)\left(1+r-\theta^{P}\right)=\tau(1-s) \theta^{P} i^{P} .
$$

They incur a higher tax cost per unit of equity. Through this specific channel, alleviating the debt bias benefits gambling banks relatively more. Nevertheless, some prudent banks may still incur larger total costs of equity, $\tau(1-s) \theta^{P} i^{P}\left(k+\varepsilon_{0}\right)$, because they raise $\varepsilon_{0}$ on top of the regulatory minimum.

\subsubsection{Equilibrium}

In parallel to the standard model, equalizing ex ante values from the two options, $V^{P}\left(\Omega^{*}\right)=$ $V^{G}\left(\Omega^{*}\right)$, determines the risk-taking cut-off:

$$
\Omega^{*}=\tilde{r}+\frac{\tau(1-s)\left(1+r-\theta^{P}\right) \varepsilon_{0}\left(i^{P} ; \Omega^{*}\right)}{(1-\tau) \Delta \theta}-\frac{\tau(1-s)}{1-\tau} k .
$$

Substituting (29) for $\varepsilon_{0}\left(i^{P} ; \Omega^{*}\right)$ gives the closed-form solution

$$
\Omega^{*}=\tilde{r}+\chi\left(1+i^{P}\right)-\frac{\tilde{\chi}\left(1+i^{\prime}\right) k}{1-\tau}, \quad \tilde{\chi} \equiv \frac{\chi \cdot\left(1+r-\theta^{G}\right)}{1+r-\theta^{P}}>\chi .
$$

Recall that $\chi \in[0,1)$ is a measure of the tax distortion defined in (20). Unless the capital standard $k$ is extremely tight, some banks raise equity in excess of the regulatory minimum to set incentives for the prudent portfolio, $\Omega^{*}<\Omega^{\circ} .{ }^{8}$ Otherwise, an alternative equilibrium will emerge in which no bank attracts voluntary equity, and capital requirements bind for all types. Banks with high specific returns will invest in the pru-

\footnotetext{
${ }^{8}$ The inequality $\Omega^{*}<\Omega^{\circ}$ requires:

$$
k<\frac{(1-\tau)(1-\chi)\left(1+i^{P}\right)}{\left(1+i^{\prime}\right)(1-\tilde{\chi})}=\frac{1-\tau}{1-\tau(1-s)} \equiv \bar{k} .
$$

The second equality uses the definition of $\chi$ in (20). This inequality plausibly holds for realistic parameter values: The corporate tax rate $\tau$ typically ranges between $20 \%$ and $30 \%$ implying that $\bar{k}$ is between $70 \%$ to $80 \%$ even if $s=1$. This ceiling is an order of magnitude higher than any typical leverage ratio.
} 
dent portfolio, whereas others might exploit the gains from gambling despite the high capital ratio. ${ }^{9}$ Our analysis focuses on capital requirements below this upper bound that are slack for some banks in equilibrium. The capital structure of the pivotal bank thus remains sensitive to taxation.

\subsubsection{Results}

We start by differentiating the pivotal type $V^{P}\left(\Omega^{*}\right)=V^{G}\left(\Omega^{*}\right)$ and get:

$$
\begin{aligned}
{\left[1-\tau-\tau(1-s) \zeta \frac{d \varepsilon_{0}}{d \Omega}\right] \cdot d \Omega^{*}=} & {\left[\Omega^{*}-\tilde{r}+(1-s) \zeta\left(\varepsilon_{0}+\tau \frac{d \varepsilon_{0}}{d \tau}\right)-(1-s) k\right] \cdot d \tau } \\
& -\tau\left[\zeta\left(\varepsilon_{0}-(1-s) \frac{d \varepsilon_{0}}{d s}\right)-k\right] \cdot d s .
\end{aligned}
$$

Again, we use $\zeta \equiv\left(1+r-\theta^{P}\right) / \Delta \theta>0$. Voluntary equity $\varepsilon_{0}$ responds to taxes in parallel to total equity $e_{0}$ in the baseline model, and it decreases in the tax rate $\tau$, the allowance for equity $s$, and the type $\Omega$. In addition to the channels emphasized earlier, the (distortionary) corporate income tax also influences risk taking by making equity relatively more costly for gambling banks on a per-unit basis. Since their risk-adjusted return on equity is higher, gambling banks are disproportionately affected by the debt bias. Through this channel, a larger ACE and a lower tax rate benefit them relatively more. These two effects are captured by the terms proportional to $k$.

LEMMA 2 The risk-taking cut-off $\Omega^{*}$ responds to the tax according to

$$
d \Omega^{*}=-\sigma_{s} \cdot d s+\sigma_{\tau} \cdot d \tau
$$

\footnotetext{
${ }^{9}$ In such an equilibrium, raising no voluntary equity, offering depositors the low interest rate $i^{P}$, and investing in the prudent portfolio is an option. It promises an ex ante bank value of $V^{P}=(1-\tau)\left(r^{P}+\right.$ $\left.\theta^{P} \Omega\right)-\tau(1-s) \theta^{P} i^{P} k$, which exceeds $V^{G}$ in (31) if the type satisfies $\Omega \geq \Omega^{\prime}=\tilde{r}-\tau(1-s) k /(1-\tau)$. Obviously, this cut-off decreases in $\tau$ and $k$ and increases in $s$. Such an allocation can only be incentivecompatible if the no-gambling condition (29) holds for all prudent banks with $\Omega \geq \Omega^{\prime}$. One can show that latter is exactly satisfied for $k=\bar{k}$.
} 
with the coefficients defined as

$$
\begin{aligned}
\sigma_{s} & =\frac{\chi(1-\chi)\left(1+i^{P}\right)^{2}}{(1-s)\left(1+i^{\prime}\right)}-\frac{\tau(1-\chi)(1+\zeta) k}{1-\tau}, \\
\sigma_{\tau} & =\frac{\chi(1-\chi)\left(1+i^{P}\right)^{2}}{\tau\left(1+i^{\prime}\right)}-\left[(1-s)(1+\zeta)+\frac{\tilde{\chi}\left(1+i^{\prime}\right)}{1-\tau}\right] \frac{(1-\chi) k}{1-\tau} .
\end{aligned}
$$

Proof: The coefficients follow from differentiating voluntary equity (29),

$$
d \varepsilon_{0}=-\frac{1-\tau}{1+i^{\prime}} \cdot d \Omega-\frac{\tau i e_{0}}{1+i^{\prime}} \cdot d s-\frac{e_{0}(1+s i)}{(1-\tau)\left(1+i^{\prime}\right)} \cdot d \tau
$$

substituting these sensitivities into (34), and rearranging.

How banks adjust risk taking to taxes depends on the magnitude of regulatory capital standards. If the latter are low, both coefficients $\sigma_{s}$ and $\sigma_{\tau}$ are positive, and banks respond to taxes much like in the baseline model. More bank invests in the prudent portfolio following an increase in the allowance for equity or a tax cut. Once capital standards are tighter, the tax sensitivities of risk taking become more ambiguous:

PROPOSITION 3 If the corporate income tax is distortionary, bank adjust risk taking differently depending on capital requirements:

- With low capital requirements, $k \leq k_{0}$, a larger tax allowance and a lower tax rate discourage risk taking (i.e., $\sigma_{s}>0$ and $\sigma_{\tau}>0$ ).

- With intermediate capital requirements, $k_{0}<k \leq k_{1}$, a larger tax allowance and a higher tax rate discourage risk taking (i.e., $\sigma_{s} \geq 0$ and $\sigma_{\tau}<0$ ).

- With high capital requirements, $k>k_{1}$, a larger tax allowance and a lower tax rate encourage risk taking (i.e., $\sigma_{s}<0$ and $\sigma_{\tau}<0$ ).

A neutral corporate income tax has no effect on bank risk taking.

Proof: The three cases follow from evaluating the coefficients in (35). Appendix A 
derives the thresholds $k_{0}$ and $k_{1}$ and proves $k_{0}<k_{1}<\bar{k}$. If the tax is neutral with $s=1$ such that $\chi=0$, the cut-off is insensitive to the tax rate, $\sigma_{\tau}=0$.

As long as minimum capital requirements are low, a more generous allowance for equity or a lower tax rate discourage risk taking. Capital standards weaken but do not fundamentally alter the tax sensitivities compared to the standard model. Although gambling banks are ceteris paribus more exposed to the debt bias, they have so little equity that differences in the per-unit tax costs of equity have negligible effects.

Once capital standards are tight, gambling banks are also well capitalized, while voluntary equity $\varepsilon_{0}$ of prudent banks is small. Hence, the fact the debt bias hurts gambling banks relatively more on a per-unit basis matters. By magnifying the debt bias, a higher tax rate therefore discourages gambling although the marginal prudent bank has more equity in total. In the same spirit, a larger tax allowance may increase risk taking whenever it benefits gambling more than prudent banks.

The role of capital regulation is especially important for how changes in the corporate tax rate influence bank risk taking. This effect already becomes positive for some intermediate capital requirements, in which case a higher tax rate as well as a larger allowance for equity discourage risk taking (second case). The reason why this level of capital standards suffices to reverse the effect of the tax rate but not of the allowance is that regulation itself reduces risk taking, see (33), and thereby diminishes the specific return of the pivotal bank $\Omega^{*}$. The gap in total returns between prudent and gambling portfolios, $r^{P}-r^{G}+\Delta \theta \Omega^{*}$, shrinks. Recall that the tax rate reduces the relative value of the prudent option both by diminishing this gap and by magnifying the debt bias. For the tax allowance, in contrast, only the second channel matters. Capital requirements thus have a more pronounced effect on how the tax rate influences risk taking. 
In the light of the empirical evidence, the first and the second case in Proposition 3 seem relevant. Low capital requirements in the range $k \leq k_{1}$ rationalize the findings that an $\mathrm{ACE}$ always reduces risk taking, while the consequences of the tax rate can be of either sign. The first case with $k \leq k_{0}$ explains the positive effect of the tax rate on bad loans found by Gambacorta et al. (2017) exactly in a subsample of weakly capitalized banks. For $k_{0}<k \leq k_{1}$, the model is consistent with Horváth (2018), who estimates that tax hikes reduce the share of non-performing loans.

Eventually, corporate tax reform and capital regulation are complementary in limiting risk taking. Provided that capital standards are not too tight (i.e., $k<k_{1}$ ), the ACE reduces gambling. Similarly, capital requirements discourage risk taking in general, see (33). ${ }^{10}$ Whenever the degree of bank risk taking is considered desirable, regulators may thus relax capital standards after a tax reform:

COROLLARY 4 An increase in the tax allowance permits regulators to relax capital requirements without weakening risk-taking incentives and increasing failure risk.

Proof: We combine $d \Omega^{*} / d k<0$ from (33) with $d \Omega^{*} / d s$ from (35) and keep the cut-off $\Omega^{*}$ unchanged:

$$
d \Omega^{*}=-\sigma_{s} \cdot d s-\frac{\tilde{\chi}\left(1+i^{\prime}\right)}{1-\tau} \cdot d k=0 \quad \Leftrightarrow \quad \frac{d k}{d s}=-\frac{\sigma_{s}(1-\tau)}{\tilde{\chi}\left(1+i^{\prime}\right)} .
$$

The implied adjustment $d k / d w$ is negative whenever $k<k_{1}$ and $\sigma_{s}>0$.

\subsection{Deposit Insurance}

Another typical feature that sets banks apart from other firms and influences capital structure and risk taking is deposit insurance. If not adequately priced, it entails an implicit subsidy for deposits, which therefore become artificially cheap.

\footnotetext{
${ }^{10}$ Only in a neutral tax system with $s=1$, risk taking is insensitive to capital requirements. Banks voluntarily raise sufficient equity once the latter is no more expensive than deposits.
} 
We consider partial deposit insurance, for which banks pay no contribution: Depositors receive a share $\nu<1$ of deposits with risk-free interest, $1+r$, whenever the bank fails. ${ }^{11}$ In reality, deposits are insured only up to a coverage limit. An alternative interpretation like in Keen and de Mooij (2016) is full insurance with probability $\nu$ and no insurance with $1-\nu$. This motivates the pricing condition:

$$
\theta\left(1+i^{j}\right)+\left(1-\theta^{j}\right) \nu(1+r)=1+r
$$

With probability $\theta^{j}$, the bank repays deposits and interest $1+i^{j}$. Otherwise, depositors only receive $\nu(1+r)$. For $\nu \rightarrow 1$, deposits are almost risk-free leading to $i^{j} \rightarrow r{ }^{12}$

Unlike in the baseline model, we now need to distinguish between the risk-adjusted return on equity and the deposit rate. The former equals $i^{j, e}$ and follows from the standard pricing condition $\theta^{j}\left(1+i^{j, e}\right)=1+r$. One immediately observes that equity is more expensive than deposits, $i^{j, e} \geq i^{j}$.

Corporate Income Tax: The tax base is profit equal to realized payoff, $\alpha_{m}+\Omega$ or $\alpha_{h}+\Omega$, net of the interest expense on deposits, $i(1-e)$. A fraction $s \in[0,1]$ of the risk-adjusted cost of equity $i^{e}$ can be deducted from the tax base. Depending on the realized payoff, the tax liability is:

$$
T_{m}=\tau\left[\alpha_{m}+\Omega-i(1-e)-s i^{e} e\right], \quad T_{h}=\tau\left[\alpha_{h}+\Omega-i(1-e)-s i^{e} e\right], \quad T_{l}=0 .
$$

We can express the expected tax depending on portfolio $j=\{G, P\}$ as:

$$
T^{j}=\tau\left[r^{j}+\theta^{j} \Omega+(1+r)-\theta^{j}(1+i)+\theta^{j}\left(i-s i^{e}\right) e\right] .
$$

\footnotetext{
${ }^{11}$ Assuming that only the principal is insured would not change the results.

${ }^{12}$ We rule out full insurance, $\nu=1$, because depositors would have no incentive to price deposits and impose the minimum equity requirement. With partial insurance, large depositors who are uninsured at the margin require a risk premium depending on the capital ratio and address the agency problem.
} 


\subsubsection{Risk Taking}

The bank's expected after-tax profit follows from substituting (38) for $T^{j}$ in (1):

$$
\pi^{j}(e, i ; \Omega)=(1-\tau)\left(r^{j}+\theta^{j} \Omega\right)+\left[(1+r)-\theta^{j}(1+i)\right](1-\tau-e)-\tau \theta^{j}\left(i-s i^{e}\right) e .
$$

Portfolio Choice and Capital Structure: For any deposit rate $i$, return on equity $i^{e}$, and capital ratio $e$, a bank chooses the prudent portfolio as long as $\pi^{P}(e, i ; \Omega) \geq \pi^{G}(e, i ; \Omega)$ or, equivalently, as long as the capital ratio satisfies:

$$
e \geq e_{0}(i ; \Omega) \equiv \frac{(1-\tau)(1+i+\tilde{r}-\Omega)}{1+i^{\prime \prime}}, \quad i^{\prime \prime} \equiv i-\tau\left(i-s i^{e}\right) .
$$

Bank Value and Deposit Rate: Banks receive an expected pre-tax subsidy worth $\bar{\nu}^{j} \equiv 1+r-\theta^{j}\left(1+i^{j}\right)=\nu(1+r)\left(1-\theta^{j}\right)$ per deposit. Profit (39) equals the after-tax economic rents consisting of expected returns and implicit subsidy net of the extra cost of equity due to both the forgone subsidy and the debt bias:

$$
\begin{aligned}
\pi^{j}\left(e, i^{j} ; \Omega\right) & =(1-\tau)\left[r^{j}+\theta^{j} \Omega+\bar{\nu}^{j}\right]-\left[\bar{\nu}^{j}+\tau \theta^{j}\left(i^{j}-s i^{j, e}\right)\right] e \\
& =(1-\tau)\left[r^{j}+\theta^{j} \Omega+\bar{\nu}^{j}(1-e)\right]-\tau(1-s) \theta^{j} i^{j, e} e
\end{aligned}
$$

The second line uses $i^{j}-i^{j, e}=-\bar{\nu}^{j} / \theta^{j}$.

Each bank must choose between the prudent and the gambling option: First, it may raise at least minimum equity $e \geq e_{0}\left(i^{P} ; \Omega\right)$, borrow at the interest rate $i^{P}$ satisfying $(36)$, and will invest in the prudent portfolio. The maximization problem is

$$
V^{P}(\Omega)=\max _{e, \lambda} \pi^{P}\left(e, i^{P}, \Omega\right)+\lambda^{P}\left[e-e_{0}\left(i^{P} ; \Omega\right)\right]
$$

with $\pi^{P}\left(e, i^{P} ; \Omega\right)$ defined in $(41)$. Since equity is more expensive than deposits due to guarantees and debt bias, and the bank exactly raises minimum equity, $e=e_{0}$. The prudent option offers $V^{P}(\Omega)=(1-\tau)\left[r^{P}+\theta^{P} \Omega+\bar{\nu}^{P}\left(1-e_{0}\right)\right]-\tau(1-s) \theta^{P} i^{P, e} e_{0}$.

Second, the bank may have a lower capital ratio $e<e_{0}\left(i^{G} ; \Omega\right)$, borrow at the high 
interest rate $i^{G}$, and will gamble:

$$
V^{G}(\Omega)=\max _{e, \lambda} \pi^{G}\left(e, i^{G} ; \Omega\right)+\lambda\left[e_{0}\left(i^{G} ; \Omega\right)-e\right]
$$

Again, the constraint is fulfilled with zero equity giving $V^{G}(\Omega)=(1-\tau)\left[r^{G}+\theta^{G} \Omega+\bar{\nu}^{G}\right]$.

\subsubsection{Equilibrium}

The pivotal type $\Omega^{*}$ is indifferent between the two options set out above, $V^{P}\left(\Omega^{*}\right)=$ $V^{G}\left(\Omega^{*}\right)$. Substituting (42) and (43) yields the cut-off:

$$
\Omega^{*}=\tilde{r}+\nu(1+r)+\frac{(1-\tau) \bar{\nu}^{P}+\tau(1-s)\left(1+r-\theta^{P}\right)}{\Delta \theta(1-\tau)} e_{0}\left(i^{P} ; \Omega^{*}\right) .
$$

Substituting for minimum equity $e_{0}\left(i^{P} ; \Omega^{*}\right)$, which depends on the cut-off according to (40), gives the closed-form solution:

$$
\Omega^{*}=\tilde{r}+\nu(1+r)+\frac{\left(\chi_{0}+\chi_{1}\right)(1+r)(1-\nu)}{\theta^{P}} .
$$

Distortions due to debt bias and mis-priced deposit insurance defined as:

$$
\begin{aligned}
\chi_{0} & =\frac{\tau(1-s)\left(1+r-\theta^{P}\right)}{\Delta \theta\left(1+i^{\prime \prime}\right)+(1-\tau) \bar{\nu}^{P}+\tau(1-s)\left(1+r-\theta^{P}\right)} \\
\chi_{1} & =\frac{(1-\tau) \bar{\nu}^{P}}{\Delta \theta\left(1+i^{\prime \prime}\right)+(1-\tau) \bar{\nu}^{P}+\tau(1-s)\left(1+r-\theta^{P}\right)} .
\end{aligned}
$$

Note $\chi_{0}+\chi_{1}<1$ as well as $\chi_{0}=0$ if the tax is neutral and $\chi_{1}=0$ with no insurance.

The cut-off is higher than in the standard model with correctly priced deposits in (19).

More banks gamble because they can profitably exploit deposit insurance.

The zero-equity cut-off is $\Omega^{\circ}=1+i^{P}+\tilde{r}=\tilde{r}+\nu(1+r)+(1+r)(1-\nu) / \theta^{P}$, and the inequality $\Omega^{*}<\Omega^{\circ}$ holds. Hence, some banks raise positive equity to set incentives for the prudent portfolio. Only in the special case of almost full insurance $\nu \rightarrow 1$, the two cut-offs would coincide, $\Omega^{*} \rightarrow \Omega^{\circ}=\tilde{r}+(1+r)$ because equity is too expensive compared to subsidized deposits. 


\subsubsection{Results}

The tax sensitivities of risk taking follow from differentiating the pivotal type determined by $V^{P}\left(\Omega^{*}\right)=V^{G}\left(\Omega^{*}\right)$ :

$$
\begin{aligned}
& {\left[1-\tau-\left(\frac{(1-\tau) \bar{\nu}^{P}}{\Delta \theta}+\tau(1-s) \zeta\right) \frac{d e_{0}}{d \Omega}\right] \cdot d \Omega^{*}=-\left[\tau \zeta e_{0}-\left(\frac{(1-\tau) \bar{\nu}^{P}}{\Delta \theta}+\tau(1-s) \zeta\right) \frac{d e_{0}}{d s}\right] \cdot d s} \\
& -\left[\tilde{r}-\Omega^{*}+\frac{\bar{\nu}^{G}-\bar{\nu}^{P}\left(1-e_{0}\right)}{\Delta \theta}-\zeta(1-s) e_{0}-\left(\frac{(1-\tau) \bar{\nu}^{P}}{\Delta \theta}+\tau(1-s) \zeta\right) \frac{d e_{0}}{d \tau}\right] \cdot d \tau .
\end{aligned}
$$

Most effects are parallel to the standard model but there is one additional channel: the implicit (pre-tax) subsidy of deposits. Taxes influence the capital structure of prudent banks and thereby their total subsidy $\bar{\nu}^{P} d=\bar{\nu}^{P}\left(1-e_{0}\right)$ but they do not affect the subsidy of gambling banks with zero equity. Both $\mathrm{ACE}$ and tax rate allow for a lower minimum capital ratio and larger deposits (see Appendix A). Through this specific channel, they magnify the implicit subsidy of prudent relative to gambling banks ${ }^{13}$ and make this option more attractive. In (46), these effect are captured by the terms proportional to $(1-\tau) \bar{\nu}^{P}$.

PROPOSITION 4 The risk-taking cut-off $\Omega^{*}$ responds to taxes according to

$$
d \Omega^{*}=-\sigma_{s} \cdot d s+\sigma_{\tau} \cdot d \tau
$$

with coefficients

$$
\begin{aligned}
\sigma_{s} & \equiv \frac{(1+r)(1-\nu)}{\theta^{P}} \frac{\chi_{0}}{1-s}\left[1-\frac{\left(\chi_{0}+\chi_{1}\right) \theta^{G}}{\theta^{P}}\right]>0, \\
\sigma_{\tau} & \equiv \frac{(1+r)(1-\nu)}{\theta^{P}} \frac{1-\chi_{0}-\chi_{1}}{1+i^{\prime \prime}} \frac{(1-s)\left(1+r-\theta^{P}\right)\left(1+i^{P}\right)-\bar{\nu}^{P}\left(1+s i^{P, e}\right)}{\Delta \theta\left(1+i^{\prime \prime}\right)+(1-\tau) \bar{\nu}^{P}+\tau(1-s)\left(1+r-\theta^{P}\right)} .
\end{aligned}
$$

A larger allowance for equity $s$ unambiguously reduces risk taking. A higher tax rate $\tau$ encourages risk taking if the debt bias is severe and the share of guaranteed deposits $\nu$ is small (i.e., $\sigma_{\tau}>0$ ) but discourages risk taking if the debt bias is small and the share of guaranteed deposits is large (i.e., $\left.\sigma_{\tau}<0\right)$.

Proof: Follows from differentiating $e_{0}$ in (40) and substituting the sensitivities into (46).

\footnotetext{
${ }^{13}$ The subsidy of gambling banks is larger due to higher asset risk and larger deposits, $\bar{\nu}^{G}>\bar{\nu}^{P} d$.
} 
Appendix A derives (47) step by step.

In the presence of deposit insurance, the ACE still discourages risk taking as the coefficient $\sigma_{s}$ is always positive due to $\chi_{0}+\chi_{1}<1$ and $\theta^{G}<\theta^{P}$. The effect of the corporate tax rate is more ambiguous, however. The sign of $\sigma_{\tau}$ crucially depends on the expression $(1-s)\left(1+r-\theta^{P}\right)\left(1+i^{P}\right)-\bar{\nu}^{P}\left(1+s i^{P, e}\right)$ reflecting two countervailing effects, namely, the debt bias and the implicit subsidy for deposits that both increase in the corporate tax rate. Provided that the share of guaranteed deposits $\nu$ is small and the tax is distortionary, a higher tax rate still induces more risk taking. However, this effect is reversed and a tax hike reduces risk taking whenever deposit insurance is more generous and the debt bias is rather small. Intuitively, prudent banks can afford a lower capital ratio without undermining incentives if the tax rate is high, which increases their implicit subsidy. Since the subsidy of gambling banks with no equity is unchanged, the higher tax rate boosts the relative value of prudent banks through this channel.

Unlike in the standard model, a neutral tax with a full allowance for equity reduces risk taking as reflected in $\sigma_{\tau}>0$. Since equity is still more expensive than deposits in a neutral system, changes in the capital structure do affect the value of prudent banks. A higher tax rate reduces risk taking, $d \Omega^{*} / d \tau_{\mid s=1}<0$, because prudent banks can earn a larger implicit subsidy. This finding departs from the neutrality result in the standard model exactly because deposit insurance distorts the pricing of risky debt. Consequently, introducing the allowance for corporate in a revenue-neutral fashion offers stability gains in two ways: The ACE itself unambiguously reduces risk taking, which is reinforced by a potential increase in the tax rate.

Financial Stability: This extension with deposit insurance allows for a richer analysis of the stability gains from corporate tax reforms. In particular, one can define the fiscal 
costs of bank failure, which prominently features in quantitative studies (e.g., Langedijk et al., 2015):

$$
C \equiv \int_{0}^{\Omega^{*}} \bar{\nu}^{G} d F(\Omega)+\int_{\Omega^{*}}^{\bar{\Omega}} \bar{\nu}^{P}\left[1-e_{0}\left(i^{P} ; \Omega\right)\right] d F(\Omega)=\nu(1+r)\left[\pi-\left(1-\theta^{P}\right) \bar{e}\right] .
$$

The fiscal costs are equal to guaranteed deposits $\nu(1+r) d$ of a failed bank. Banks with a low specific return $\Omega<\Omega^{*}$ are entirely financed with deposits, $d=1$, and gamble leading to costs of $\bar{\nu}^{G}=\nu(1+r)\left(1-\theta^{G}\right)$ per bank. More profitable ones with $\Omega>\Omega^{*}$ cause a smaller expected cost $\bar{\nu}^{P} d=\nu(1+r)\left(1-\theta^{P}\right)\left(1-e_{0}\right)$ because they invest in safer assets, $\theta^{P}>\theta^{G}$, and only partly financed with deposits, $d=1-e_{0}$. The second equality expresses the expected fiscal costs as a function of the average failure probability $\pi$ in (24) and the aggregate capital ratio of the banking sector $\bar{e}$ in (25).

How taxation influences these two measures determines its net effect on the fiscal costs: The average probability of failure decreases in the ACE because fewer banks gamble, while the effect of a higher tax rate is more ambiguous depending on the share of guaranteed deposits $\nu$ (see Proposition 4). As shown in Section 3.3, the aggregate capital ratio adjusts at extensive and intensive margins. Taxes affect the share of banks with positive equity as well as the minimum capital ratio $e_{0}$ of each bank with positive equity. In case of a larger tax allowance, these effects tend to offset each other but Appendix A shows that aggregate equity increases at least if types are uniformly distributed. The effects of the corporate tax rate depend on the extent of insurance, which determines how a tax hike affects risk taking.

COROLLARY 5 The expected fiscal costs respond to taxes according to

$$
d C=\nu(1+r)\left[\left(\frac{d \pi}{d s}-\left(1-\theta^{P}\right) \frac{d \bar{e}}{d s}\right) \cdot d s+\left(\frac{d \pi}{d \tau}-\left(1-\theta^{P}\right) \frac{d \bar{e}}{d \tau}\right) \cdot d \tau\right] .
$$

A larger allowance for equity reduces the expected fiscal cost due to lower insolvency risk and higher aggregate equity. Provided that the share of guaranteed deposits is small and 
the tax is distortionary, a lower corporate tax rate has a comparable effect.

Proof: Recall $d \pi=\Delta \theta f\left(\Omega^{*}\right) \cdot d \Omega^{*}, d \bar{e}=-e_{0}^{*} \cdot d \Omega^{*}+\int_{\Omega^{*}}^{\Omega^{\circ}} d e_{0} d F(\Omega)$ as well as $d e_{0} / d s<$ 0 and $d e_{0} / d \tau<0$ from differentiating (40). On account of (47), a larger allowance reduces failure risk, $d \pi / d s=-\Delta \theta f\left(\Omega^{*}\right) \sigma_{s}<0$. Appendix A proves $d \bar{e} / d s>0$ giving $d C / d s<0$. The tax rate affects the fiscal cost according to $d \pi / d \tau=\Delta \theta f\left(\Omega^{*}\right) \sigma_{\tau}$ and $d \bar{e} / d \tau=-e_{0}^{*} \sigma_{\tau}+\int_{\Omega^{*}}^{\Omega^{\circ}}\left(d e_{0} / d \tau\right) d F(\Omega)$ with $d e_{0} / d \tau<0$. If $\sigma_{\tau}>0$, we have $d \pi / d \tau>0$ and $d \bar{e} / d \tau<0$ giving $d C / d \tau>0$.

The finding that that the ACE unambiguously lowers the fiscal costs of guarantees is consistent with quantitative results. Unlike prior studies that emphasize a decrease in bank leverage as the source of reduced fiscal costs, stability gains in this model emerge because banks are less levered on average and invest in safer portfolios. Moreover, simple tax cuts only reduce the fiscal cost if the debt bias is pronounced and insurance is limited and might be counterproductive otherwise. This casts some doubts about using tax cuts to enhance financial stability: It they are effective, either an alternative is available (i.e., the ACE) or guarantees are small and their fiscal cost no first-order concern.

Welfare: In the presence of deposit insurance, welfare consists of the aggregate surplus of the banking sector and the tax revenue net of the fiscal costs of guarantees, $W=$ $V+T-C$. The latter are not internalized by banks. Taken together, it is equal to the aggregate economic returns of banks, see $(27) \cdot{ }^{14}$

The welfare effects of risk taking represented by the cut-off $\Omega^{*}$ follow from evaluating

\footnotetext{
${ }^{14}$ It follows from substituting the definitions

$$
V \equiv \int_{0}^{\Omega^{*}} V^{G}(\Omega) d F(\Omega)+\int_{\Omega^{*}}^{\bar{\Omega}} V^{P}(\Omega) d F(\Omega), \quad T \equiv \int_{0}^{\Omega^{*}} T^{G} d F(\Omega)+\int_{\Omega^{*}}^{\bar{\Omega}} T^{P}(\Omega) d F(\Omega)
$$

and (48) into $W=V+T-C$. The ex ante values $V^{P}$ and $V^{G}$ are given by (42) and (43), and the expected tax revenue with deposit rates set by (36) equals $T^{j}=\tau\left[r^{j}+\theta^{j} \Omega+\bar{\nu}^{j}(1-e)+(1-s) \theta^{j} i^{j, e} e\right]$.
} 
the corresponding first-order condition in market equilibrium (45):

$$
\begin{aligned}
d W & =-\left(\Omega^{*}-\tilde{r}\right) \Delta \theta f\left(\Omega^{*}\right) \cdot d \Omega^{*} \\
& =-\left[\nu(1+r)+\frac{\left(\chi_{0}+\chi_{1}\right)(1+r)(1-\nu)}{\theta^{P}}\right] \Delta \theta f\left(\Omega^{*}\right) \cdot d \Omega^{*}<0 .
\end{aligned}
$$

There is excessive risk taking: On the one hand, the debt bias $\left(\chi_{0}>0\right)$ hampers the use of equity in setting proper incentives. On the other hand, mis-priced deposit insurance $\left(\nu>0\right.$ and $\left.\chi_{1}>0\right)$ magnifies this effect and exacerbate risk shifting. The latter is a classical externality: Banks ignore that insolvency causes fiscal costs proportional to deposits, which is why too many banks raise no equity and gamble.

Taking into account how taxes affect the cut-off (Proposition 4), a larger ACE is unambiguously welfare-improving because it facilitates the use of equity and thereby reduces excessive risk-taking. The welfare effects of the corporate tax rate are more ambiguous depending on the extent of deposit insurance, however. Eventually, risk taking is excessive even in a neutral tax system $\left(\chi_{0}=0\right)$ because mis-priced deposit insurance causes an externality that favors gambling.

\section{Conclusion}

The stability of a bank rests on sufficient equity that provides a safety net and helps absorb losses as well as on a safe, well-diversified loan portfolio. Stability gains from a corporate tax reform addressing the debt bias can thus result from smaller leverage and lower portfolio risk. This paper provides a first theoretical analysis of the risk-taking channel and develops a principal-agent model that emphasizes the incentive function of equity. Corporate taxation matters because it typically renders equity more expensive than deposits and thereby hampers the use of equity in solving the bank's agency problem and in limiting risk taking. 
Our analysis yields three main results: First, an allowance for corporate equity and a lower corporate tax rate discourage bank risk taking thereby improving financial stability and welfare. Intuitively, these policies mitigate the debt bias in taxation and facilitate the use of equity as a disciplining device that helps set proper incentives.

Second, the corporate income tax has no effect on risk taking if it is neutral and treats debt and equity symmetrically. This property mirrors prior results in the business taxation literature. Since risk taking is insensitive to tax rate changes in this case, governments can introduce a full ACE in a revenue-neutral fashion thereby unambiguously reducing risk taking and enhancing financial stability.

Third, capital regulation and deposit insurance influence the tax sensitivities of bank risk taking. These typical features of banks can rationalize the more ambiguous effects of the corporate tax rate observed in the data. A tax hike may actually reduce risk taking either if regulatory capital requirements are tight or if deposit insurance is generous.

\section{References}

Allen, F. and D. Gale (2000). Comparing Financial Systems. Cambridge and London: MIT Press.

Auerbach, A. J. (2002). Taxation and Corporate Financial Policy. In A. J. Auerbach and M. Feldstein (Eds.), Handbook of Public Economics, Volume 3, pp. 1251-1292. North Holland.

Besanko, D. and G. Kanatas (1996). The Regulation of Bank Capital: Do Capital Standards Promote Bank Safety? Journal of Financial Intermediation 5(2), 160-183.

Bond, S., K. Y. Ham, G. Maffini, A. Nobili, and G. Ricotti (2016). Regulation, Tax and Capital Structure: Evidence from Administrative Data on Italian Banks. Bank of Italy 
Occasional Paper No. 361.

Bond, S. R. and M. P. Devereux (1995). On the Design of a Neutral Business Tax under Uncertainty. Journal of Public Economics 58, 57-71.

Boyd, J. H. and G. De Nicolò (2005). The Theory of Bank Risk Taking and Competition Revisited. Journal of Finance 60(3), 1329-1343.

Célérier, C., T. Kick, and S. Ongena (2019). Taxing Bank Leverage: The Effects on Bank Portfolio Allocation. Working Paper.

De Mooij, R., M. Keen, and M. Orihara (2014). Taxation, Bank Leverage, and Financial Crises. In R. de Mooij and G. Nicodème (Eds.), Taxation and Regulation of the Financial Sector, pp. 229-278. MIT Press.

Devereux, M. P., N. Johannesen, and J. Vella (2015). Can Taxes Tame the Banks? Evidence from European Bank Levies. Saïd Business School Research Paper No. 13/25.

Diamond, D. W. (1984). Financial Intermediation and Delegated Monitoring. Review of Economic Studies 51(3), 393-414.

Gambacorta, L., G. Ricotti, S. Sundaresan, and Z. Wang (2017). The Effects of Tax on Bank Liability Structure. BIS Working Paper, No. 611.

Graham, J. R. (2003). Taxes and Corporate Finance: A Review. Review of Financial Studies 16(4), 1075-1129.

Graham, J. R. (2008). Taxes and Corporate Finance. In E. Eckbo (Ed.), Handbook of Empirical Corporate Finance, Volume 2, pp. 60-133. Elsevier.

Gu, G., R. de Mooij, and T. Poghosyan (2015). Taxation and Leverage in International Banking. International Tax and Public Finance 22, 177-200.

Hakenes, H. and I. Schnabel (2011). Capital regulation, bank competition, and financial stability. Economics Letters 113, 256-258. 
Hellmann, T. F., K. C. Murdock, and J. E. Stiglitz (2000). Liberalization, Moral Hazard in Banking, and Prudential Regulation: Are Capital Requirements Enough? American Economic Review 90(1), 147-165.

Hemmelgarn, T. and D. Teichmann (2014). Tax Reforms and the Capital Structure of Banks. International Tax and Public Finance 21, 645-693.

Horváth, B. L. (2018). The Interaction of Bank Regulation and Taxation. Working Paper.

Keeley, M. C. (1990). Deposit Insurance, Risk and Market Power in Banking. American Economic Review 80(5), 1183-1200.

Keen, M. and R. de Mooij (2016). Debt, Taxes, and Banks. Journal of Money, Credit and Banking 48(1), 5-33.

Langedijk, S., G. Nicodème, A. Pagano, and A. Rossi (2015). Debt Bias in Corporate Income Taxation and the Costs of Banking Crises. European Commission Taxation Papers No. 50.

Martin-Flores, J. and C. Moussu (2018). Is Bank Capital Sensitive to a Tax Allowance on Marginal Equity? European Financial Management, forthcoming.

Martinez-Miera, D. and R. Repullo (2017). Search for Yield. Econometrica 85(2), 351378.

Repullo, R. (2004). Capital Requirements, Market Power, and Risk-Taking in Banking. Journal of Financial Intermediation 13(2), 452-490.

Repullo, R. (2013). Cyclical Adjustment of Capital Requirements: A Simple Framework. Journal of Financial Intermediation 22(3), 608-626.

Schepens, G. (2016). Taxes and Bank Capital Structure. Journal of Financial Economics 120, 585-600. 


\section{A Appendix: Proofs}

Proof of Corollary 1: Tax revenue is equal to aggregate tax payments of prudent and gambling banks

$$
T \equiv \int_{0}^{\Omega^{*}} T^{G} d F(\Omega)+\int_{\Omega^{*}}^{\bar{\Omega}} T^{P}(\Omega) d F(\Omega)
$$

with $T^{P}$ and $T^{G}$, defined in (10). We compute the change in tax revenues due to an increase in the tax allowance $s$ from 0 to 1 and note the ranking of risk-taking and zero-equity cut-offs, $\Omega_{\mid s=1}^{*}=\tilde{r}<\tilde{r}+\chi_{\mid s=0}\left(1+i^{P}\right)=\Omega_{\mid s=0}^{*}<\Omega^{\circ}$ :

$$
T_{\mid s=0}-T_{\mid s=1}=\tau \cdot\left[\int_{\Omega_{\mid s=0}^{*}}^{\Omega^{\circ}}\left(1+r-\theta^{P}\right) e_{0}\left(i^{P} ; \Omega\right) d F(\Omega)-\Delta \theta \int_{\Omega_{\mid s=1}^{*}}^{\Omega_{\mid s=0}^{*}}(\Omega-\tilde{r}) d F(\Omega)\right] .
$$

The first integral reflects the smaller tax base as the cost of equity of all prudent banks that need positive equity, $\Omega \in\left[\Omega_{\mid s=0}^{*}, \Omega^{\circ}\right]$, is made tax-deductible. The second integral represents reduced risk taking due to the reform as types $\Omega \in\left[\Omega_{\mid s=1}^{*}, \Omega_{\mid s=0}^{*}\right]$ switch from the gambling to the prudent portfolio. This behavioral effect is negative due to $\Omega \geq \tilde{r}$ for these banks (i.e., the expected pre-tax return from the prudent portfolio is larger).

The introduction of an ACE may a priori raise or lower tax depending on magnitude of these countervailing effects. Revenue declines as long as many banks need to raise large equity $e_{0}$, which is made tax deductible, and either the difference in expected returns or the fraction of banks switching to the prudent portfolio and thus the increase in pre-tax return are small. If types are uniformly distributed, $F(\Omega)=\Omega / \bar{\Omega}$ such that $\Omega^{\circ}-\Omega_{\mid s=0}^{*}=(1-\chi)\left(1+i^{P}\right)$ and $\Omega_{\mid s=0}^{*}-\Omega_{\mid s=1}^{*}=\chi\left(1+i^{P}\right)$, the revenue falls provided that the corporate tax rate is not too high:

$$
T_{\mid s=0}-T_{\mid s=1}=\frac{\Delta \theta\left(1+i^{P}\right)^{2} \chi_{\mid s=0}\left(1-\tau-\chi_{\mid s=0}\right)}{2 \bar{\Omega}} .
$$

In any case, the tax rate $\tau$ can be adjusted after the full allowance is introduced to offset any changes in tax revenue caused by the ACE. Since it does not affect portfolio de- 
cisions anymore and thus leaves the tax base unchanged, a higher tax rate unambiguously increases revenue:

$$
\frac{d T}{d \tau}_{\mid s=1}=\int_{0}^{\Omega^{*}} r^{G}+\theta^{G} \Omega d F(\Omega)+\int_{\Omega^{*}}^{\bar{\Omega}} r^{P}+\theta^{G} \Omega(\Omega) d F(\Omega)>0 .
$$

Proof of Corollary 2: We need to show that a larger allowance for equity $s$ raises aggregate equity in (26) if types are uniformly distributed:

$$
\begin{aligned}
\frac{d \bar{e}}{d s} & =\int_{\Omega^{*}}^{\Omega^{\circ}} \frac{d e_{0}(\Omega)}{d s} d F(\Omega)-e_{0}^{*} f\left(\Omega^{*}\right) \frac{d \Omega^{*}}{d s} \\
& =-\frac{\tau i^{P}}{1+i^{\prime}} \int_{\Omega^{*}}^{\Omega^{\circ}} e_{0}(\Omega) d F(\Omega)+e_{0}^{*} f\left(\Omega^{*}\right) \sigma_{s} \\
& =\frac{1}{\bar{\Omega}}\left[e_{0}^{*} \sigma_{s}-\left.\frac{\tau i^{P}}{1+i^{\prime}} \frac{(1-\tau)\left[(1+i+\tilde{r}) \Omega-\Omega^{2} / 2\right]}{1+i^{\prime}}\right|_{\Omega^{*}} ^{\Omega^{\circ}}\right] \\
& =\frac{1}{\bar{\Omega}}\left[e_{0}^{*} \sigma_{s}-\frac{(1-\tau) \tau i^{P}}{1+i^{\prime}}\left(\frac{(1+i+\tilde{r})\left(\Omega^{\circ}-\Omega^{*}\right)}{1+i^{\prime}}-\frac{\Omega^{\circ 2}-\Omega^{* 2}}{2\left(1+i^{\prime}\right)}\right)\right] \\
& =\frac{1}{\bar{\Omega}}\left[e_{0}^{*} \sigma_{s}-\frac{(1-\tau) \tau i^{P}}{1+i^{\prime}} \frac{\Omega^{\circ}-\Omega^{*}}{1+i^{\prime}}\left(\Omega^{\circ}-\frac{\Omega^{\circ}+\Omega^{*}}{2}\right)\right] \\
& =\frac{e_{0}^{*}}{\bar{\Omega}}\left[\sigma_{s}-\frac{\tau i^{P}}{1+i^{\prime}} \frac{\Omega^{\circ}-\Omega^{*}}{2}\right]=\frac{e_{0}^{*}}{\bar{\Omega}}\left[\sigma_{s}-\frac{\tau i^{P}}{2} \frac{e_{0}^{*}}{1-\tau}\right] \\
& =\frac{e_{0}^{* 2}}{(1-\tau) \bar{\Omega}}\left[\frac{\left(1+i^{P}\right) \chi}{1-s}-\frac{\tau i^{P}}{2}\right] \\
& =\frac{\tau i^{P} e_{0}^{* 2}}{2(1-\tau) \bar{\Omega}} \frac{\theta^{P}\left(1+i^{P}\right)+\theta^{G}\left(1+i^{\prime}\right)}{\Delta \theta\left(1+i^{\prime}\right)+\tau(1-s) \theta^{P} i^{P}}>0 .
\end{aligned}
$$

We use $\Omega^{\circ}=1+i+\tilde{r}, e_{0}^{*}=(1-\tau)(1-\chi)\left(1+i^{P}\right) /\left(1+i^{\prime}\right)$, and $\Omega^{\circ}-\Omega^{*}=(1-\chi)\left(1+i^{P}\right)=$ $e_{0}^{*}\left(1+i^{\prime}\right) /(1-\tau)$.

Proof of Proposition 3: A larger tax allowance decreases the risk-taking cut-off if

$$
\sigma_{s}>0 \quad \Leftrightarrow \quad k<\frac{\chi(1-\tau)\left(1+i^{P}\right)^{2}}{\tau(1-s)(1+\zeta)\left(1+i^{\prime}\right)} \equiv k_{1} .
$$

Similarly, a higher tax rate increases the risk-taking cut-off if

$$
\sigma_{\tau}>0 \Leftrightarrow \quad k<\frac{\chi(1-\tau)\left(1+i^{P}\right)^{2}}{\tau\left(1+i^{\prime}\right)\left[(1-s)(1+\zeta)+\frac{\tilde{\chi}\left(1+i^{P}\right)}{1-\tau}\right]}=\frac{k_{1}}{1+\frac{\tilde{\chi}\left(1+i^{P}\right)}{(1-\tau)(1-s)(1+\zeta)}} \equiv k_{0} .
$$


Obviously, we have $k_{0}<k_{1}$ : For some capital requirements, both a larger allowance for equity and a higher tax rate reduce the risk-taking cut-off.

One eventually needs to check whether capital requirements above those thresholds, $k>k_{0}$ and $k>k_{1}$, are feasible and that they do not become binding for all types. Noting $k_{0}<k_{1}$, it suffices to show that $k_{1}<\bar{k}$ always holds:

$$
\begin{aligned}
& k_{1}=\frac{\chi(1-\tau)\left(1+i^{P}\right)^{2}}{\tau(1-s)(1+\zeta)\left(1+i^{\prime}\right)}<\frac{(1-\tau)(1-\chi)\left(1+i^{P}\right)}{(1-\tilde{\chi})\left(1+i^{\prime}\right)}=\bar{k} \\
& \Leftrightarrow \quad \frac{\chi\left(1+i^{P}\right)}{\tau(1-s)(1+\zeta)}<\frac{1-\chi}{1-\tilde{\chi}} \\
& \Leftrightarrow \quad \frac{\left(1+r-\theta^{P}\right)\left(1+i^{P}\right)}{(1+\zeta)}=\frac{\Delta \theta \zeta\left(1+i^{P}\right)}{(1+\zeta)}<\frac{\Delta \theta\left(1+i^{\prime}\right)}{1-\tilde{\chi}} \\
& \Leftrightarrow \quad \frac{1+r-\theta^{P}}{1+r-\theta^{G}}(1-\tilde{\chi})\left(1+i^{P}\right)=\frac{1+r-\theta^{P}}{1+r-\theta^{G}}\left(1+i^{P}\right)-\chi\left(1+i^{P}\right)<1+i^{\prime} \\
& \Leftrightarrow \quad \frac{\theta^{P}\left(1+i^{P}\right)}{1+r-\theta^{G}}+\tau(1-s) i^{P}\left[\frac{\theta^{P}\left(1+i^{P}\right)}{\Delta \theta\left(1+i^{\prime}\right)+\tau(1-s)\left(1+r-\theta^{P}\right)}-1\right]>0 \\
& \Leftrightarrow \quad \frac{\theta^{P}\left(1+i^{P}\right)}{1+r-\theta^{G}}+\tau(1-s) i^{P} \frac{\theta^{G}\left(1+i^{\prime}\right)}{\Delta \theta\left(1+i^{\prime}\right)+\tau(1-s)\left(1+r-\theta^{P}\right)}>0,
\end{aligned}
$$

which uses the definition of $\chi$ in $(20)$ and $\zeta=\left(1+r-\theta^{P}\right) / \Delta \theta$.

Proof of Proposition 4: We derive the coefficients $\sigma_{s}$ and $\sigma_{\tau}$ following (48) step by step. Equation (46) results from differentiating $V^{P}\left(\Omega^{*}\right)=V^{G}\left(\Omega^{*}\right)$ together with

$$
\begin{aligned}
d V^{P}= & (1-\tau) \theta^{P} \cdot d \Omega-\left[(1-\tau) \bar{\nu}^{P}+\tau(1-s) \theta^{P} i^{P, e}\right] \cdot d e_{0}+\tau \theta^{P} i^{P, e} e_{0} \cdot d s \\
& -\left[r^{P}+\theta^{P} \Omega+\bar{\nu}^{P}\left(1-e_{0}\right)+(1-s) \theta^{P} i^{P, e} e_{0}\right] \cdot d \tau, \\
d V^{G}= & (1-\tau) \theta^{G} \cdot d \Omega-\left[r^{G}+\theta^{G} \Omega+\bar{\nu}^{G}\right] \cdot d \tau .
\end{aligned}
$$

The minimum capital ratio $e_{0}$ in (40) responds to changes in specific return, tax allowance and tax rate as follows:

$$
d e_{0}=-\frac{1-\tau}{1+i^{\prime \prime}} \cdot d \Omega-\frac{\tau i^{P, e} e_{0}}{1+i^{\prime \prime}} \cdot d s-\frac{\left(1+s i^{P, e}\right) e_{0}}{(1-\tau)\left(1+i^{\prime \prime}\right)} \cdot d \tau .
$$

Recall $i^{\prime \prime} \equiv i^{P}-\tau\left(i^{P}-s i^{P, e}\right)$. To avoid cumbersome notation, we define:

$$
\bar{\zeta} \equiv(1-\tau) \bar{v}^{P}+\tau(1-s) \theta^{P} i^{P, e}, \quad \bar{\sigma} \equiv \frac{(1+r)(1-\nu)}{\theta^{P}}, \quad \bar{\chi} \equiv \chi_{0}+\chi_{1} .
$$


Noting the definitions of $\chi_{0}$ and $\chi_{1}$ following equation (45), the first equation suggests $\bar{\chi} / \bar{\zeta}=(1-\bar{\chi}) / \Delta \theta\left(1+i^{\prime \prime}\right)$

We substitute the sensitivities of minimum equity into (46) and get

$$
\begin{aligned}
\varphi \cdot d \Omega^{*}= & -\tau e_{0}\left[\zeta+\frac{\bar{\zeta}}{\Delta \theta} \frac{i^{P, e}}{1+i^{\prime \prime}}\right] \cdot d s \\
& -\left[\tilde{r}-\Omega^{*}+\frac{\bar{\nu}^{G}-\bar{\nu}^{P}\left(1-e_{0}\right)}{\Delta \theta}-\zeta(1-s) e_{0}+\frac{\bar{\zeta}}{\Delta \theta} \frac{\left(1+s i^{P, e}\right) e_{0}}{(1-\tau)\left(1+i^{\prime \prime}\right)}\right] \cdot d \tau
\end{aligned}
$$

with $\varphi \equiv(1-\tau)\left[1+\bar{\zeta} / \Delta \theta\left(1+i^{\prime \prime}\right)\right]=(1-\tau) /(1-\bar{\chi})$; the second equality substitutes for the short-cut $\bar{\zeta}$. Using $\zeta \equiv \theta^{P} i^{P, e} / \Delta \theta$ and factoring out $i^{P, e}$ on the first and substituting for $\tilde{r}-\Omega^{*}$ from (45) together with $\left(\bar{\nu}^{G}-\bar{\nu}^{P}\right) / \Delta \theta=(1+r) \nu$ on the second line yields:

$$
\begin{aligned}
\varphi \cdot d \Omega^{*}= & -\tau e_{0} i^{P, e}\left[\frac{\theta^{P}}{\Delta \theta}+\frac{\bar{\zeta}}{\Delta \theta\left(1+i^{\prime \prime}\right)}\right] \cdot d s \\
& +\left[\bar{\chi} \bar{\sigma}+\left(\zeta(1-s)-\frac{\bar{\nu}^{P}}{\Delta \theta}\right) e_{0}-\frac{\bar{\zeta}}{\Delta \theta} \frac{\left(1+s i^{P, e}\right) e_{0}}{(1-\tau)\left(1+i^{\prime \prime}\right)}\right] \cdot d \tau \\
= & -\tau e_{0} i^{P, e}\left[\frac{\theta^{P}}{\Delta \theta}+\frac{\bar{\chi}}{1-\bar{\chi}}\right] \cdot d s \\
& +\left[\bar{\chi} \bar{\sigma}+\frac{(1-s) \theta^{P} i^{P, e}-\bar{\nu}^{P}}{\Delta \theta} e_{0}-\frac{\bar{\zeta}}{\Delta \theta} \frac{\left(1+s i^{P, e}\right) e_{0}}{(1-\tau)\left(1+i^{\prime \prime}\right)}\right] \cdot d \tau .
\end{aligned}
$$

In the next step, we substitute the equilibrium capital ratio of the pivotal bank $e_{0}\left(i^{P}, \Omega^{*}\right)=(1-\tau)(1-\bar{\chi}) \bar{\sigma} /\left(1+i^{\prime \prime}\right)$, which follows from combining (40) and (45), and divide by $1-\tau$ :

$$
\begin{aligned}
\frac{1}{1-\bar{\chi}} \cdot d \Omega^{*}= & -\frac{(1-\bar{\chi}) \bar{\sigma}}{1+i^{\prime \prime}} \tau i^{P, e}\left[\frac{\theta^{P}}{\Delta \theta}+\frac{\bar{\chi}}{1-\bar{\chi}}\right] \cdot d s \\
& +\frac{\bar{\sigma}}{1-\tau}\left[\bar{\chi}+\frac{\left[(1-s) \theta^{P} i^{P, e}-\bar{\nu}^{P}\right](1-\tau)(1-\bar{\chi})}{\Delta \theta\left(1+i^{\prime \prime}\right)}-\frac{\bar{\zeta}(1-\bar{\chi})}{\Delta \theta\left(1+i^{\prime \prime}\right)} \frac{1+s i^{P, e}}{1+i^{\prime \prime}}\right] \cdot d \tau \\
= & -\frac{\bar{\sigma}}{1+i^{\prime \prime}} \tau i^{P, e}\left[\frac{\theta^{P}(1-\bar{\chi})}{\Delta \theta}+\bar{\chi}\right] \cdot d s \\
& +\frac{\bar{\sigma}}{1-\tau}\left[\bar{\chi}+\frac{\left[(1-s) \theta^{P} i^{P, e}-\bar{\nu}^{P}\right](1-\tau)(1-\bar{\chi})}{\Delta \theta\left(1+i^{\prime \prime}\right)}-\bar{\chi} \frac{1+s i^{P, e}}{1+i^{\prime \prime}}\right] \cdot d \tau
\end{aligned}
$$

Below, we multiply by $1-\bar{\chi}$ and decompose $\bar{\chi}=\chi_{0}+\chi_{1}$ to rewrite the expression in square brackets on the second line. We then use $\chi_{0}=\tau \theta^{P}(1-s) i^{P, e} \bar{\chi} / \bar{\zeta}$ and substitute the distortions $\chi_{0}$ and $\chi_{1}$ to finally obtain the net responses of the risk-taking cut-off to 
changes in tax allowance and tax rate:

$$
\begin{aligned}
d \Omega^{*}= & -\frac{\bar{\sigma}(1-\bar{\chi})}{\Delta \theta\left(1+i^{\prime \prime}\right)} \frac{\Delta \theta}{\theta^{P}} \tau \theta^{P} i^{P, e}\left[\frac{\theta^{P}(1-\bar{\chi})}{\Delta \theta}+\bar{\chi}\right] \cdot d s \\
& +\frac{\bar{\sigma}(1-\bar{\chi})}{1-\tau}\left[\chi_{0}\left(\frac{1}{\tau}-\frac{1+s i^{P, e}}{1+i^{\prime \prime}}\right)-\chi_{1} \frac{1+s i^{P, e}}{1+i^{\prime \prime}}\right] \cdot d \tau \\
= & -\frac{\bar{\sigma} \chi_{0}}{1-s} \frac{\Delta \theta}{\theta^{P}}\left[\frac{\theta^{P}}{\Delta \theta}-\frac{\bar{\chi} \theta^{G}}{\Delta \theta}\right] \cdot d s \\
& +\frac{\bar{\sigma}(1-\bar{\chi})}{(1-\tau)\left(1+i^{\prime \prime}\right)}\left[\frac{\chi_{0}}{\tau}\left(1+i^{P}\right)-\frac{\chi_{1}\left(1+s i^{P, e}\right)}{1-\tau}\right] \cdot d \tau \\
= & -\frac{\bar{\sigma} \chi_{0}}{1-s}\left[1-\frac{\bar{\chi} \theta^{G}}{\theta^{P}}\right] \cdot d s \\
& +\frac{\bar{\sigma}(1-\bar{\chi})}{1+i^{\prime \prime}} \frac{(1-s)\left(1+r-\theta^{P}\right)\left(1+i^{P}\right)-\bar{\nu}^{P}\left(1+s i^{P, e}\right)}{\Delta \theta\left(1+i^{\prime \prime}\right)+(1-\tau) \bar{\nu}^{P}+\tau(1-s)\left(1+r-\theta^{P}\right)} \cdot d \tau .
\end{aligned}
$$

Proof of Corollary 5: In parallel to the proof of Corollary 2, we demonstrate that a larger allowance for equity $s$ also raises aggregate capital ratio in (26) in the presence of guarantees. We use the derivative of $e_{0}$ in (40) as well as the zero-equity cut-off $\Omega^{\circ}=1+i^{P}+\tilde{r}$ together with the equilibrium relations

$$
\begin{aligned}
e_{0}^{*} & =\frac{(1-\tau)(1-\bar{\chi})(1+r)(1-\nu)}{\theta^{P}\left(1+i^{\prime \prime}\right)}, \\
\Omega^{\circ}-\Omega^{*} & =\frac{(1-\bar{\chi})(1+r)(1-\nu)}{\theta^{P}}=\frac{e_{0}^{*}\left(1+i^{\prime \prime}\right)}{1-\tau}, \\
\frac{\chi_{0}}{1-\bar{\chi}} & =\frac{\tau(1-s) \theta^{P} i^{P, e}}{\Delta \theta\left(1+i^{\prime \prime}\right)}, \\
\sigma_{s} & =\frac{e_{0}^{*}}{1-\tau} \frac{1+i^{\prime \prime}}{1-s} \frac{\chi_{0}}{1-\bar{\chi}}\left[1-\frac{\bar{\chi} \theta^{G}}{\theta^{P}}\right]=\frac{\tau \theta^{P} i^{P, e} e_{0}^{*}}{\Delta \theta(1-\tau)}\left[1-\frac{\bar{\chi} \theta^{G}}{\theta^{P}}\right] .
\end{aligned}
$$


The tax allowance positively affects aggregate equity:

$$
\begin{aligned}
\frac{d \bar{e}}{d s} & =\int_{\Omega^{*}}^{\Omega^{\circ}} \frac{d e_{0}(\Omega)}{d s} d F(\Omega)-e_{0}^{*} f\left(\Omega^{*}\right) \frac{d \Omega^{*}}{d s} \\
& =\frac{1}{\bar{\Omega}}\left[e_{0}^{*} \sigma_{s}-\frac{(1-\tau) \tau i^{P}}{1+i^{\prime \prime}}\left(\frac{(1+i+\tilde{r})\left(\Omega^{\circ}-\Omega^{*}\right)}{1+i^{\prime \prime}}-\frac{\Omega^{\circ 2}-\Omega^{* 2}}{2\left(1+i^{\prime \prime}\right)}\right)\right] \\
& =\frac{1}{\bar{\Omega}}\left[e_{0}^{*} \sigma_{s}-\frac{(1-\tau) \tau i^{P, e}}{2}\left(\frac{\Omega^{\circ}-\Omega^{*}}{1+i^{\prime \prime}}\right)^{2}\right]=\frac{e_{0}^{*}}{\bar{\Omega}}\left[\sigma_{s}-\frac{\tau i^{P, e}}{2} \frac{e_{0}^{*}}{1-\tau}\right] \\
& =\frac{e_{0}^{* 2}}{(1-\tau) \bar{\Omega}}\left[\frac{1+i^{\prime \prime}}{1-s} \frac{\chi_{0}}{1-\bar{\chi}}\left(1-\frac{\theta^{G} \bar{\chi}}{\theta^{P}}\right)-\frac{\tau i^{P}}{2}\right] \\
& =\frac{\tau i^{P, e} e_{0}^{* 2}}{(1-\tau) \bar{\Omega}}\left[\frac{\theta^{P}}{\Delta \theta}\left(1-\frac{\theta^{G} \bar{\chi}}{\theta^{P}}\right)-\frac{1}{2}\right] \\
& =\frac{\tau i^{P, e} e_{0}^{* 2}}{2(1-\tau) \bar{\Omega}} \frac{\theta^{P}\left(1+i^{P}\right)+\theta^{G}\left(1+i^{\prime \prime}\right)+\bar{\nu}^{P}}{\Delta \theta\left(1+i^{\prime \prime}\right)+\tau(1-s) \theta^{P} i^{P, e}+(1-\tau) \bar{\nu}^{P}}>0 .
\end{aligned}
$$




\section{B Appendix: Supplementary Material}

\section{B.1 Tax Treatment of Profits and Losses}

In our analysis, the tax treats profits and losses asymmetrically and allows for the deduction of risk-adjusted costs of debt and equity. This appendix demonstrates that this approach combined with a full $\mathrm{ACE}, s=1$, is equivalent to a tax that treats profits and losses symmetrically and only allows for the deduction of the risk-free rate like the neutral business tax suggested by Bond and Devereux (1995).

The neutral business tax falls on economic rents. The tax base encompasses portfolio and bank-specific returns plus any changes in the value of assets minus the risk-free rate. The value of assets is unchanged and equal to 1 whenever the portfolio net return is positive (i.e., $\alpha_{m}$ or $\alpha_{h}$ ). For the zero gross return, however, the value of assets drops from 1 to 0 leading to a loss of 1 . Accordingly, tax liability and rebate are:

$$
T_{m}=\tau\left(\alpha_{m}+\Omega-r\right), \quad T_{h}=\tau\left(\alpha_{h}+\Omega-r\right), \quad T_{l}=-\tau(1+r) .
$$

The expected tax burden from portfolio $j=\{G, P\}$ is proportional to economic rents:

$$
T^{j}=\tau\left[\theta^{j}\left(\alpha_{m}+\Omega\right)+\theta_{h}^{j} \Delta \alpha-\left(1-\theta^{j}\right)-r\right]=\tau\left[r^{j}+\theta^{j} \Omega\right] .
$$

Bank owners only pay the tax if a positive portfolio return is realized and the bank is solvent. Since the tax rebate in the default state $T_{l}$ is appropriated by depositors, only the expected tax burden conditional on solvency matters for owners:

$$
\bar{T}^{j}=\tau\left[\theta^{j}\left(\alpha_{m}+\Omega-r\right)+\theta_{h}^{j} \Delta \alpha\right]=\tau\left[r^{j}+\theta^{j} \Omega+(1+r)\left(1-\theta^{j}\right)\right] .
$$

We use the conditional tax burden to compute the bank's expected after-tax profit:

$$
\begin{aligned}
\pi^{j}(e, i ; \Omega) & =r^{j}+\theta^{j} \Omega+\left[(1+r)-\theta^{j}(1+i)\right](1-e)-\bar{T}^{j} \\
& =(1-\tau)\left(r^{j}+\theta^{j} \Omega\right)+\left[(1+r)-\theta^{j}(1+i)\right](1-e)-\tau(1+r)\left(1-\theta^{j}\right) .
\end{aligned}
$$


Portfolio Choice and Capital Structure: Each bank chooses the prudent portfolio as long as $\pi^{P}(e, i ; \Omega)-\pi^{G}(e, i ; \Omega) \geq 0$. Substituting (B.4) yields the minimum capital ratio which prevents gambling:

$$
e \geq e_{0}(i ; \Omega) \equiv \frac{(1-\tau)(\tilde{r}-\Omega)+1+i-\tau(1+r)}{1+i} .
$$

Deposit Rate: The failed bank receives the tax rebate $T_{l}=\tau(1+r)$, which is appropriated by its creditors. Each depositor thus gets a pro-rata share $1 / d=1 /(1-e)$ of this rebate if the bank fails and charges a deposit rate that satisfies:

$$
\theta^{j}\left(1+i^{j}\right)+\frac{\left(1-\theta^{j}\right) \tau(1+r)}{1-e}=1+r
$$

Whenever this condition is fulfilled, expected profit equals the after-tax economic returns and is independent of the capital structure:

$$
V^{j}(\Omega)=\pi^{j}\left(e, i^{j} ; \Omega\right)=(1-\tau)\left(r^{j}+\theta^{j} \Omega\right)
$$

Profit is equal to the ex ante value in the baseline model with a tax on profits and a full allowance for corporate equity, see (14) and (16).

Equilibrium: Each bank compares ex ante values. The pivotal type follows from $V^{P}\left(\Omega^{*}\right)=V^{G}\left(\Omega^{*}\right)$ and is given by $\Omega^{*}=\tilde{r}$. This cut-off, which is insensitive to taxes, is exactly the same that results in the baseline model with a full ACE, $s=1$, see (18). Consequently, risk-taking decisions of banks are the same (i) in a tax system that treats profits and losses symmetrically by granting a rebate to loss-making (failed) banks and allows for the deduction of the risk-free cost of total capital and (ii) in a system with a tax on profits only that allows for the deduction of the risk-adjusted cost of total capital. 


\section{B.2 Charter Value}

The bank-specific return $\Omega$ can be interpreted as the charter value (i.e., the present value of future bank profits), which prominently features in the risk-taking literature. This extension endogenizes the charter value and thereby provides one micro-foundation for the specific return. It also demonstrates that the tax sensitivities of risk taking are consistent with the standard model with a reduced-form charter value pictured as a taxable return.

Dynamic model: Following Hellmann et al. (2000), banks operate for $T \rightarrow \infty$ periods. They raise deposits and equity, invest in either of the two portfolios, and pay out dividends if successful in each period. Portfolio returns and the risk-free rate are constant over time. In case of failure, the bank exits and its license is revoked. ${ }^{15}$

Denoting the per-period expected profit from portfolio $j=\{G, P\}$ by $\tilde{\pi}_{t}^{j}$, the discounted value of future bank profits is $\pi^{j}=\sum_{t=0}^{T}\left(\delta \theta^{j}\right)^{t} \tilde{\pi}_{t}^{j}$ where $\delta$ is the discount factor. Banks will choose their strategies corresponding to an infinitely repeated Nash equilibrium. Omitting time indices, discounted expected profits equal $\pi^{j}=\tilde{\pi}^{j} /\left(1-\delta \theta^{j}\right)$.

To preserve heterogeneity, we assume that banks differ in their discount factors $\delta \in$ $[0,1]$, which are observable and distributed with cumulative density $F_{t}(\delta)$. Intuitively, some banks are more forward-looking than others, for example, due to different time preferences of owners or managers. One might argue that privately owned banks tend to focus more on creating long-term value, while publicly traded banks owned by dispersed shareholders put more emphasis on the current performance.

In parallel to the standard model, the per-period after-tax profit from portfolio $j$

\footnotetext{
${ }^{15}$ For each bank which exits, the regulator assigns a license to a new bank to preserve a competitive banking market.
} 
equals $\tilde{\pi}^{j}(e, i ; \delta)=(1-\tau) r^{j}+\left[(1+r)-\theta^{j}(1+i)\right](1-\tau-e)-\tau(1-s) \theta^{j} i e$. With constant capital structure and interest rates, the discounted charter value of a bank with portfolio $j$ is the defined as the present value of future profits:

$$
\Omega_{\delta}^{j} \equiv \frac{\delta}{1-\delta \theta^{j}} \frac{\tilde{\pi}^{j}(e, i ; \delta)}{1-\tau} .
$$

Accordingly, total bank profit can be written as the sum of the expected profit in the current period and the discounted charter value after taxes:

$$
\begin{aligned}
\pi^{j}(e, i ; \delta) & =\tilde{\pi}^{j}(e, i ; \delta)+(1-\tau) \theta^{j} \Omega_{\delta}^{j} \\
& =(1-\tau)\left(r^{j}+\theta^{j} \Omega_{\delta}^{j}\right)+\left[(1+r)-\theta^{j}(1+i)\right](1-\tau-e)-\tau(1-s) \theta^{j} i e .
\end{aligned}
$$

The second line expresses the total profit in parallel to (11) as after-tax economic returns plus a limited liability effect minus the extra cost of bank equity. Unlike in the baseline model, the charter value is endogenous and depends on portfolio, capital structure and deposit rate, see (B.8).

Portfolio Choice and Capital Structure: Each bank invests in the prudent portfolio as long as $\pi^{P} \geq \pi^{G}$. Substituting for total profits and charter values and dividing by $\Delta \theta$ gives the no-gambling condition ${ }^{16}$

$$
(1-\tau) \tilde{r}+(1+i)(1-e)-\tau[1+i-(1-s) i e] \leq(1-\tau) \Omega_{\delta}^{P}
$$

It requires that the short-term gains from gambling due to higher net returns and exploiting limited liability must not exceed the long-term loss of charter value because of a higher probability of failure. One can solve this condition for the minimum capital ratio. Unlike in the baseline model, the charter value also depends on the capital ratio, and one obtains after some calculations:

$$
e_{0}(i ; \delta)=(1-\tau) \tilde{e}_{0}(i ; \delta), \quad \tilde{e}_{0} \equiv \frac{1+i+\tilde{r}-\tilde{\delta}\left[r^{P}+(1+r)-\theta^{P}(1+i)\right]}{1+i^{\prime}-\tilde{\delta}\left[(1+r)-\theta^{P}(1+i)+\tau(1-s) \theta^{P} i\right]} .
$$

This formulation uses the definitions $\tilde{\delta} \equiv \delta /\left(1-\delta \theta^{P}\right)$ and $i^{\prime} \equiv i[1-\tau(1-s)]$.

\footnotetext{
${ }^{16}$ First substitute (B.8) for $\Omega_{\delta}^{G}$ and multiply both sides by $1-\delta \theta^{G}$ such that the r.h.s. is simply $\tilde{\pi}^{G}$.
} 
Equilibrium: Deposits are priced according to $\theta^{j}\left(1+i^{j}\right)=1+r$ in each period. Banks can offer the low interest rate $i^{P}$ only if their capital ratio satisfies $e \geq e_{0}\left(i^{P} ; \delta\right)$ such that the prudent portfolio is incentive-compatible.

Since the debt bias renders equity more expensive than deposits, it immediately follows that prudent banks exactly raise minimum equity $e_{0}=(1-\tau) \tilde{e}_{0}\left(i^{P} ; \delta\right)$, while gambling banks raise no equity altogether. The corresponding ex ante values are:

$$
\begin{aligned}
& V^{P}(\delta)=\pi^{P}\left(e_{0}, i^{P} ; \delta\right)=\frac{(1-\tau)\left[r^{P}-\tau(1-s)\left(1+r-\theta^{P}\right) \tilde{e}_{0}(\delta)\right]}{1-\delta \theta^{P}}, \\
& V^{G}(\delta)=\pi^{G}\left(0, i^{G} ; \delta\right)=\frac{(1-\tau) r^{G}}{1-\delta \theta^{G}} .
\end{aligned}
$$

The first expression uses the equilibrium capital ratio of a prudent bank in (B.11) with a risk-adjusted deposit rate,

$$
e_{0}(\delta)=(1-\tau) \tilde{e}_{0}(\delta), \quad \tilde{e}_{0}(\delta) \equiv \frac{1+r+\theta^{P}\left(\tilde{r}-\tilde{\delta} r^{P}\right)}{1+r-\tau(1-s)\left(1+r-\theta^{P}\right)\left(1+\tilde{\delta} \theta^{P}\right)} .
$$

Unlike in the standard model, the risk-taking cut-off $\delta^{*}$ is defined in terms of the discount factor. It is determined by $V^{P}\left(\delta^{*}\right)=V^{G}\left(\delta^{*}\right)$ or, after substituting (B.12),

$$
\frac{r^{P}-\tau(1-s)\left(1+r-\theta^{P}\right) \tilde{e}_{0}\left(\delta^{*}\right)}{1-\delta^{*} \theta^{P}}=\frac{r^{G}}{1-\delta^{*} \theta^{G}} .
$$

Taxes influence this cut-off only via the extra cost of equity $\tau(1-s)\left(1+r-\theta^{P}\right) \tilde{e}_{0}\left(\delta^{*}\right)$.

Comparative Statics: We differentiate $V^{P}\left(\delta^{*}\right)=V^{G}\left(\delta^{*}\right)$, which are both defined in (B.12), and substitute the sensitivities of the equilibrium capital ratio. The latter follow from differentiating (B.11), which implies $d e_{0}=(1-\tau) \cdot d \tilde{e}_{0}-\tilde{e}_{0} \cdot d \tau$ together with

$$
\begin{aligned}
d \tilde{e}_{0}= & -\frac{\theta^{P}}{\left(1-\delta \theta^{P}\right)^{2}} \frac{r^{P}-\tau(1-s)\left(1+r-\theta^{P}\right) \tilde{e}_{0}}{1+r-\tau(1-s)\left(1+r-\theta^{P}\right)\left(1+\tilde{\delta} \theta^{P}\right)} \cdot d \delta \\
& +\frac{\tilde{e}_{0}\left(1+r-\theta^{P}\right)\left(1+\tilde{\delta} \theta^{P}\right)}{1+r-\tau(1-s)\left(1+r-\theta^{P}\right)\left(1+\tilde{\delta} \theta^{P}\right)}[(1-s) \cdot d \tau-\tau \cdot d s] .
\end{aligned}
$$

The first term is always positive on account of (B.14). Forward-looking banks with a high discount factors value continuation more and can thus afford a lower capital ratio without weakening risk-taking incentives. A larger tax allowance permits banks to reduce 
equity, whereas the effect of a higher tax rate on the capital ratio is more ambiguous. ${ }^{17}$

By substituting this result, rearranging and collecting terms, one observes that the risk-taking cut-off $\delta^{*}$ responds to taxes according to

$$
\sigma_{\delta} \cdot d \delta^{*}=-\sigma_{s} \cdot d s+\sigma_{\tau} \cdot d \tau
$$

with coefficients

$$
\begin{aligned}
\sigma_{\delta} & =\frac{\Delta \theta V}{\left(1-\delta \theta^{P}\right)^{2}}\left[\frac{1-\delta \theta^{P}}{1-\delta \theta^{G}}+\frac{\tau(1-s) \theta^{P} \zeta}{1+r-\tau(1-s)\left(1+r-\theta^{P}\right)\left(1+\tilde{\delta} \theta^{P}\right)}\right]>0, \\
\sigma_{s} & =\frac{\tau\left(1+r-\theta^{P}\right) e_{0}}{1-\delta \theta^{P}} \frac{1+r}{1+r-\tau(1-s)\left(1+r-\theta^{P}\right)\left(1+\tilde{\delta} \theta^{P}\right)}>0, \\
\sigma_{\tau} & =\frac{(1-s)\left(1+r-\theta^{P}\right) e_{0}}{1-\delta \theta^{P}} \frac{1+r}{1+r-\tau(1-s)\left(1+r-\theta^{P}\right)\left(1+\tilde{\delta} \theta^{P}\right)}>0 .
\end{aligned}
$$

Note $V \equiv V^{P}\left(\delta^{*}\right)=V^{G}\left(\delta^{*}\right)$ for the pivotal type. All coefficients are positive such that a larger tax allowance and a lower corporate tax rate lower the cut-off $\delta^{*}$ and discourage risk taking. These effects are qualitatively similar to the baseline model with a reducedform charter value modeled as a specific, taxable return. Again, a neutral tax with $s=1$ does not affect risk taking as the coefficient $\sigma_{\tau}$ is zero in this case.

\footnotetext{
${ }^{17} \mathrm{~A}$ tax hike lowers also depresses the charter value, which is captured by the increase in $\tilde{e}_{0}$. The net effect follows from substituting for $d \tilde{e}_{0}$ :

$$
\frac{d e_{0}}{d \tau}=-\frac{\tilde{e}_{0}\left[1+r-(1-s)\left(1+r-\theta^{P}\right)\left(1+\tilde{\delta} \theta^{P}\right)\right]}{1+r-\tau(1-s)\left(1+r-\theta^{P}\right)\left(1+\tilde{\delta} \theta^{P}\right)} .
$$

It is usually negative in particular if the tax system is neutral with $s \rightarrow 1$ or if the bank is myopic with $\delta \rightarrow 0$. Otherwise, the effect of smaller future profits can be quite strong for forward-looking banks, and the capital ratio may rise with the tax rate for $\delta \rightarrow 1$.
} 